\title{
Marinos y colonos fenicios codificando la costa atlántica africana
}

\author{
Phoenician Seamen and Colonists codifying the African \\ Atlantic Coast
}

\begin{abstract}
Fernando López PARDO
Publicado por primera vez en J. M. CAndau Morón - F. J. GonzÁlez Ponce - A. L. ChÁvez ReIno (coords.), Libyae lustrare extrema. Realidad y literatura en la visión grecorromana de África. Homenaje al Prof. Jehan Desanges, Sevilla, 2008, 25-51
\end{abstract}

A finales del segundo milenio y a principios del primero, ${ }^{1}$ la creciente llegada por mar de gentes del Mediterráneo oriental a la fachada atlántica peninsular y a la marroquí supuso un cambio cualitativo importante. Los marinos del mar interior acopiaron y contrastaron información sobre el Océano, sus costas, las gentes que las habitaban y sus recursos y fueron forjando un imaginario atlántico que tuvo un impacto muy duradero en las mentalidades de griegos y fenicios, cuya nota más destacada era la imagen hostil de este mar, paulatinamente asociada a la idea de que atesoraba extraordinarias riquezas en ganados y metales. Riquezas más valoradas si cabe por la dificultad de acceder hasta ellas navegando en medio de múltiples peligros. Es indudable que los fenicios que transitaban esta línea de costa y los que se asentaron en ella fueron dando nombre primero a los accidentes geográficos más significativos y a los cauces fluviales de mayor caudal y naturalmente a sus nuevas factorías y colonias. El rastro de esas denominaciones aparentemente habría sucumbido, salvo casos excepcionales, ante la geografía griega y helenística referida a los confines, que habría desarrollado una cartografía con denominaciones propias o a lo sumo de origen autóctono. Y si algo había quedado de la tradición fenicio-púnica, ésta desapareció tras la conquista y colonización romana. Sin embargo creemos que ello está lejos de ser cierto y, como veremos, los esfuerzos fenicios a la hora de nombrar y designar lugares iban encaminados a servir de referencia a los navegantes y en menor medida a insertar este paisaje en su imaginario mítico-religioso.

Por otro lado, quisiera reseñar que este trabajo, así como muchos de los que he venido haciendo en los últimos años, hubieran sido imposibles si no es a partir del magistral análisis hermenéutico realizado por Jehan Desanges sobre los textos clásicos que recogen noticias sobre la costa africana. Además, no sólo sus publicaciones, sino

\footnotetext{
1 La redacción del presente artículo es resultado de los trabajos desarrollados en el ámbito del Proyecto de Investigación, subvencionado por el Ministerio de Educación y Ciencia en los planes de I+D, Náutica mediterránea y navegaciones oceánicas en la antigüedad. Fundamentos interdisciplinares (históricos, arqueológicos, iconográficos y etnográficos) para su estudio. La cuestión de la fachada atlántica afrocanaria (HUM2006-05196), de la Universidad Complutense de Madrid.
} 
también su forma de trabajar y en ocasiones sus comentarios han guiado las empresas de algunos de nosotros.

\section{Un nombre especialmente antiguo para el estuario del Lukos: $l k \check{s}$}

La ensenada de la embocadura del río Lucos debió ser punto de atraque repetido de naves del Mediterráneo oriental mucho antes de que se fundara un asentamiento permanente en el fondo de la rada, Lixus. Vemos en el propio nombre de la colonia y del río que la acogió, $L k s ̌$, una fonética y un significado estrechamente vinculados con los términos que se refieren a "los confines" (lqṣm y lksm) en los textos ugaríticos del segundo milenio. Lqșm y $l \mathrm{ksm}$ constituían el escenario mítico confinal al que llegaba su deidad solar antes de emprender su "viaje nocturno", una deliciosa pradera costera próxima al mundo de los muertos. Esta caracterización de los límites tiene muchos elementos comunes con los peírata gaíes homéricos, los confines de la tierra. Allí se encuentran prados idílicos próximos al profundo Tártaro. ${ }^{2}$ Este escenario se corresponde puntualmente con el Jardín de las Hespérides que algunas fuentes clásicas sitúan en Lixus. Según esta tradición, que creemos heredada del mundo cananeo y fenicio, en dicho ámbito occidental también el sol abandonaba su carro y se instalaba en la copa que le llevaba placenteramente en su recorrido nocturno. Efectivamente, se trata de saberes compartidos cuya transmisión debió realizarse en los puertos del Egeo y los del Levante, jugando Chipre un papel importante para su mixtura. Por lo tanto, la frecuentación de los levantinos de la Edad del Bronce, que seguramente ya codificaron el paisaje extremo-occidental, propició que al fundarse Lixus fuera elegido el nombre que la vieja categorización mítica le había atribuido antes al lugar. Se explicaría así coherentemente la tradición lixita que hacía del santuario de Melqart al lado del Jardín de las Hespérides, en el estuario del Lucos, el más antiguo del Extremo Occidente, anterior al de Melqart de Gadir. ${ }^{3}$

Hoy por hoy, Lixus parece ser el establecimiento fenicio más antiguo de la costa atlántica africana. La localidad ya tenía vocación urbana en el s. VIII a.C. cuando no antes, a fines del s. IX a.C., si extrapolamos a cronologías absolutas calibradas la datación de los materiales procedentes de los sondeos y excavaciones realizados en distintos lugares del hábitat. ${ }^{4} \mathrm{Su}$ considerable dimensión en época tan antigua permite incluir Lixus en el restringido grupo de ciudades fenicias de ese momento en el Extremo Occidente, un fenómeno urbano señalado por algunas fuentes ${ }^{5}$ que contrasta con el reducido tamaño de la mayoría de los enclaves fenicios de esa época. El análisis de las abundantes cerámicas hechas sin torno de las primeras unidades estratigráficas de los sondeos realizados en el yacimiento arqueológico, permite asegurar que el proyecto urbano fenicio de la extensa colina se realizó integrando población

\footnotetext{
2 Hom. Il. VIII, 477-481.

3 LóPez PARDo 2004-2005, 326-328.

4 Habibi 1992; López Pardo 2000.

5 Cf. Str. I, 3, 2.
} 
autóctona e indígenas traídos del sur de la península, quizás de la costa oriental de Andalucía y seguramente en régimen de dependencia. ${ }^{6}$

Lixus fue desde esa época el gran centro regional de la fachada atlántica africana, atribuyéndosele una cierta equiparación con $\mathrm{Gadir}^{7}$ y con Cartago, como señala explícitamente Plinio refiriéndose a una época pasada. ${ }^{8}$ Además del prestigioso y antiguo santuario de Melqart que se encontraba en una isla del estuario, la ciudad contaba intramuros con un recinto sacro de grandes dimensiones a juzgar por los vestigios de época mauritana y romana hallados en la plataforma inferior de la colina. Aunque últimamente se ha dudado del carácter cultual de esta área, de debajo de uno de los edificios del cambio de era procede un ánfora R1 arcaica con un graffiti de contenido cultual o votivo y un pie de figura de terracota de presunto uso sacro, entre un conjunto muy homogéneo de materiales de la segunda mitad del s. VIII-inicios del VII a.C., hallados en el interior de una estructura que parece contemporánea, lo cual nos permite asegurar que la plataforma de los templos ya fue definida como un espacio de uso cultual desde época fenicia arcaica. ${ }^{9}$

Como ya hemos señalado, las condiciones portuarias del golfo estuarino del Lucos eran excelentes y la ciudad contaba además con un embarcadero protegido por la propia colina del asentamiento, cuyas estructuras romanas son aún visibles. Ello convirtió el puerto en refugio y punto de partida para los barcos que se aventuraban en la navegación hacia el sur, fue así un lugar de memoria donde se debían conservar informaciones útiles de anteriores travesías. De alguna manera es reflejo de este papel el que Hanón, según su conocido Periplo, llevara en sus naves a algunos lixitas con el fin de que le sirvieran de intérpretes y que, a la postre, fueran los que iban indicando los nombres de los parajes que visitaban.

\section{Los eremboi visitados por Menelao, habitantes del "monte de las viñas"}

Tras el conflicto troyano, el príncipe Menelao, después de un recorrido perfectamente coherente que le conduce primero a Chipre, después a Fenicia y más tarde a Egipto, relata que sus naves le llevaron hasta los etíopes, los sidonios, los erembos y Libia, ${ }^{10}$ para después arribar a la isla de Faros, frente a Egipto. ${ }^{11}$

Desde la Antigüedad es muy poco lo que ha podido afirmarse con seguridad sobre el lugar donde habitaban los erembos, pues excepto los comentarios a este pasaje de la Odisea, este etnónimo no es recogido en fuentes antiguas. También muy inciertas han sido las reconstrucciones del itinerario que las naves de Menelao realizaron supuestamente tras abandonar Egipto.

6 López Pardo - SuÁrez Padilla 2002, 118-123.

7 Str. XVII, 3, 2.

8 Plin. Nat. Hist. V, 2, 4.

9 López Pardo - Ruiz Cabrero 2005.

10 Hom. Od. IV, 81-84: "De cierto yo sé que sufrí grandemente, que he pasado ocho años errante en mis naves, llevado ya a las costas de Chipre y Fenicia, ya a tierras de egipcios; que llegué a los etíopes, sidonios y erembos y a Libia" (trad. de Pabón en Fernández Galiano - Pabón, 2000).

11 Hom. Od. IV, 351-359. 
Estrabón ${ }^{12}$ parece preferir la interpretación de los erembos como árabes, aunque considera la corrección realizada por Zenón del texto odiseico, de 'E $\rho \in \mu \beta \omega \nu$ por "A $\alpha \beta \alpha \varsigma,{ }^{13}$ superflua, al creer que el nombre antiguo recogido en la Odisea habría sufrido consecutivas alteraciones. Siguiendo a Posidonio reconoce un aire de familia tanto étnica como de nombre entre armenios, árabes y erembos, considerando este último un epíteto particular que habría servido a los antiguos griegos para designar a los

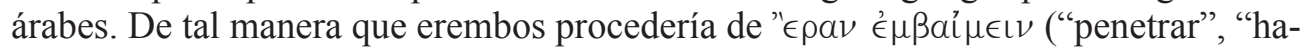
bitar bajo tierra"), calificativo que habría sido cambiado posteriormente por el más

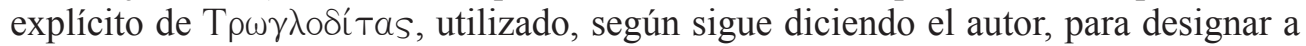
los árabes instalados entre Egipto y Etiopía. ${ }^{14}$ La Periegesis de Prisciano ${ }^{15}$ insiste en situar los Erembi mencionados en la Odisea en el país de los etíopes, en tierras de Egipto. Por su parte nos dice Estrabón ${ }^{16}$ que él mismo pudo recoger de la obra Sobre los viajes de Menelao del gramático alejandrino Aristónico todas las hipótesis sobre este viaje, que el autor ofrece de forma resumida. ${ }^{17}$ Entre ellas destaca por innecesaria según Estrabón aquella "de los que afirman que navegó hasta Etiopía unos conducen su periplo a través de Gadeira hasta la India, conciliando la duración del viaje con el tiempo que indica diciendo "volví en el octavo año»". ${ }^{18}$ Sería Crates de Malo (s. II a.C.) quien habría hecho esta propuesta, ${ }^{19}$ modificando Erembous por Eremnous (referido a la tez oscura) y considerando que se refiere a habitantes de la India. ${ }^{20}$

Estrabón, sin embargo, aparenta cambiar de opinión en el libro III y deriva el viaje de Menelao hasta el Extremo Occidente, ${ }^{21}$ considerando que el autor de la Odisea tuvo conocimiento de su expedición y de las de Diomedes, Odiseo y otros muchos a estos parajes. A no ser que tuviera en mente que después de traspasar las Columnas las naves del héroe habían circunnavegado África hasta el país de los etíopes orientales. ${ }^{22}$ Quizás su convencimiento de la deriva de los barcos de Menelao hasta el Extremo Occidente proceda de otros versos homéricos en los que Néstor refiere que Menelao "llegó hace poco del extraño país desde donde nunca espera volver hombre alguno una vez que le arrastran a través de aquel piélago inmenso los raudos ciclones". ${ }^{23}$ Unos versos que claramente parecen remitir al Océano en su parte occidental. Un dato quizás relevante es que las naves de Menelao difícilmente pudieron

12 Str. I, 2, 34.

13 Heubeck - West - Hainsworth 1988, 198.

14 Ya en I, 1, 3 Estrabón adelanta su preferencia por considerar a los erembos como trogloditas árabes situándolos en un contexto oceánico.

15 Priscilian. Perieg. 170; 890; 896.

16 Str. I, 2, 31.

17 KIDD 1988, 953.

18 Str. I, 2, 31. Trad. THA IIB, 635-636.

19 Str. I, 2, 35.

20 Str. XVI, 4, 27. Desanges 1978, 82, n. 282; THA IIB, 635.

21 Str. III, 2, 13.

22 Lo que recordaría mucho la propuesta de Crates de Malo.

23 "Mas con todo te exhorto a que vayas al gran Menelao, que hace poco llegó del extraño país desde donde nunca espera volver hombre alguno una vez que le arrastran a través de aquel piélago inmenso los raudos ciclones. Ni a las aves se ve que lo crucen de nuevo en el año, que en verdad es ingente y temible" (Hom. Od. III, 317-322). 
llevarle directamente desde las aguas del Mediterráneo al Mar Rojo y al país de los etíopes orientales, pues sobre el carácter exclusivamente naval de su expedición no caben dudas en el texto odiseico, ${ }^{24}$ ya que son sus naves las que les hacen errar desde Chipre hasta los etíopes, sidonios, erembos y finalmente Libia.

Quizás el escollo que debió parecer más destacable para proponer un viaje sólo al Extremo Occidente fuera la mención de los etíopes, pero el autor de la Odisea era consciente de que los etíopes habitaban tanto el extremo suroriental de África como el confín de Occidente, "Mas el dios (Posidón) se marchó donde los etíopes lejanos, los etíopes repartidos en el confín del género humano, en su doble dominio, unos hacia el poniente, los otros hacia la aurora". ${ }^{25}$ Residían, pues, por debajo de Libia en los extremos africanos del recorrido solar, por ello su referencia a los etíopes no por fuerza debe imaginarse en el ámbito oriental. Con posterioridad son numerosas las referencias a poblaciones melanodermas sitas en la costa atlántica africana que pertenecen a un reconocimiento empírico y no pura invención, según vemos por la insistencia en los textos y lo preciso de su localización. Entre los distintos autores antiguos que mencionan a estos etíopes de Occidente, cabe destacar al Ps.-Escílax, ${ }^{26}$ que describe a los etíopes "sagrados" que viven frente a la isla de Kérnē, que debían tener una localización no muy alejada de la isla de Mogador (vid. infra). Según el Periplo de Hanón ${ }^{27}$ etíopes nada hospitalarios habitaban una zona hacia el sur que frecuentaba el pueblo que ocupaba las orillas del río Lixos (Lukkos). Los etíopes Hesperii (occidentales) fueron objeto de atención para Eratóstenes (s. III a.C.) ${ }^{28} \mathrm{y}$ Estrabón localizaba su país en la costa por debajo de Maurousia y contra ellos intervino el rey mauritano Bogo. ${ }^{29}$ Por su parte, Plinio, ${ }^{30}$ además de referirse también a los etíopes Hesperii , a dos días de navegación a lo largo de la costa desértica, a partir de una isla llamada Atlantis, enfrente del Atlas, consideraba etíopes a los Nigritae y los Pharusii ${ }^{31}$ y habla de los etíopes Daratitae, situados al borde del mar $^{32}$ en torno al uadi Draa. ${ }^{33}$ Por su parte Tolomeo menciona con cierta profusión tribus de la costa atlántica africana a las que aplica el epíteto "etíopes", como los Leukaethiopes al norte del Draa, que habitaban seguramente la llanura de Marrakech ${ }^{34}$ y los etíopes Nigritae $^{35}$ al norte del Nigeir. ${ }^{36}$

24 Hom. Od. IV, 82.

25 Hom. Od. I, 22-26.

26 Ps. Scyl. CXII.

27 Hano 7.

28 Str. XVIII, 3, 8.

29 Str. XVII, 3, 5.

30 Plin. Nat. Hist. V, 16.

31 Plin. Nat. Hist. V, 10.

32 Plin. Nat. Hist. V, 43.

33 Desanges 1962, 213 y 227; Plinio menciona también a los etíopes Perorsi, que según el autor tocan el Océano en el límite de la Mauritania (Plin. Nat. Hist. VI, 195), a quienes por localización y nombre quizás haya que identificar con los Pharusii (Desanges 1962, 212 y 233).

34 Ptol. IV, 6, 6. Desanges 1962, 16.

35 Ptol. IV, 6, 3.

36 Desanges 1962, 207. 
Tolomeo sitúa los etíopes Hesperii al sur de los Ikthyophagi, ribereños del gran golfo del Océano occidental, también llamado Hesperios,${ }^{37}$ el cual parece comenzar

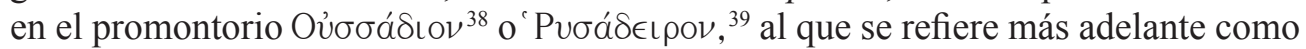

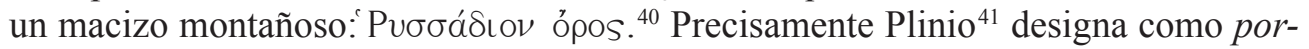
tus Rhysaddir ${ }^{42}$ la que debía ser una bahía cerca de la actual Agadir, quizás conformada por el estuario del río Sous sin sus aportes aluviales recientes y protegida por el gran promontorio del cabo Ghir, contrafuerte del Alto Atlas. El portus del $r$ 's' $d r$ (*Ruš-addir) sería naturalmente el fondeadero del "cabo imponente". ${ }^{43}$

Toda esta información permite delimitar un vasto territorio en el que habitaban pueblos denominados etíopes en la Antigüedad, entre el uadi Tensift con la llanura de Marrakech por la que discurre, el Alto Atlas y las tierras desérticas por las que fluye el uadi Draa.

No habría pues ninguna dificultad en situar la visita a los etíopes, sidonios y erembos más allá de las Columnas de Heracles, como ya vio W. von Soden, ${ }^{44}$ que muy

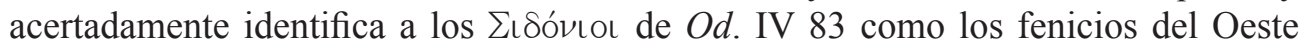
y los Eremboi como pueblos occidentales autóctonos. Con la idea de que su nombre habría derivado de Érebo, término usado con frecuencia para referirse al mundo infernal del Ocaso, al parecer derivado del hebreo 'æræb, "tarde, atardecer". ${ }^{45}$ Sin embargo puede parecer chocante que el autor de la Odisea, buen conocedor del término Érebo, ${ }^{46}$ hubiera nombrado a los habitantes de sus proximidades, los supuestos erembos, haciendo irreconocible la relación entre ambos términos.

Creemos que en la Odisea pudo ofrecerse un recorrido menos fantasioso y menos alejado de la realidad geográfica conocida en los siglos IX y VIII a.C. del Extremo Occidente. Si, como acabamos de ver, la referencia a los etíopes y sidonios de más allá del estrecho parece perfectamente coherente, no tendría por qué no serlo para los erembos.

Aunque Posidonio, según recoge Estrabón,${ }^{47}$ propone corregir Erembous en Arambous simplemente para apuntalar una relación con los arameos y los árabes, ${ }^{48}$ es posible que su estancia en Gades $c a$. 135-50 a.C. recogida en su desaparecido tratado Sobre el Océano ${ }^{49}$ y comentada por Estrabón, le hubiera permitido recordar el nom-

37 Ptol. IV, 6, 1.

38 Ptol. IV, 6, 2 (edición de Müller 1883-1901); transcrito por Roget 1924: Pointe d'Oussadion.

39 Este último según uno de los mejores manuscritos (DESANGES 1978, 138; LIPINSKi 2004, 467.

40 Ptol. IV, 6, 8.

41 Plin. Nat. Hist. V, 9.

42 Portum rhysaddir $A$ : rhisaddir $F 3$ risardir $D C h F E a C C o X$ risardis $R$ adir $F 1$ (Desanges 1980, 49).

43 López Pardo 2007, 138; la traducción sería “cap puissant” (Desanges 1978, 135), “cap (du) Puissant” (LIPINSKI 1992) o volviendo a la tesis tradicional: "Powerful Cape" (LIPINSKI 2004, 466).

44 Von SODEN 1959.

45 JeNNi 1978-1985, col. 977; “evening” (HoftiJzer - JongELing 1995, 886), que en púnico pudo tener una evolución semántica referida a "desolation” ( $r b h$ Pún; HaLfF 1963-1964, nº 51, 3).

46 "A las sombras de ocaso y el Érebo" (Hom. Od. XII 81).

47 Str. I, 2, 34.

48 KIDD 1988, 955.

49 THA IIB, 554. 
bre de la colonia de Arambys citada en el Periplo de Hanón..$^{50}$ Una de las cinco cuya fundación atribuye al cartaginés el autor de la obrita y que fueron supuestamente emplazadas en la exigua franja costera comprendida entre el cabo Espartel y Lixus.

Ello nos pone tras una pista bastante segura. Evidentemente el texto odiseico no pudo remitir al nombre de la colonia hanoniana localizable en este paraje cercano al cabo Espartel, incluso en el caso de que la supuesta fundación cartaginesa no fuera más que una simple apropiación literaria del nombre de un asentamiento fenicio anterior. El nombre de Arambys parece tomado de un topónimo semita más antiguo que se refiere al entorno geográfico del cabo Espartel que sería conocido como har 'anbin o mejor har 'anbi, como ya propuso en su día S. Bochart. ${ }^{51}$

El término $h r$ "monte" aparece documentado en distintas lenguas semíticas desde el ugarítico, ${ }^{52}$ pasando por el hebreo ${ }^{53}$ y naturalmente en fenicio-púnico, donde $h r$ tiene el significado de "montaña(s)", "país de las montañas". ${ }^{54}$ Por su parte " $n b$ se documenta en hebreo y arameo con el significado de "grape" ${ }^{55}$ En fenicio, a pesar de que quienes han tratado el tema no lo han encontrado, aunque consideran muy probable su presencia ${ }^{56}$ creemos que se halla atestiguado formando parte de algún nombre teóforo como "NBTB ' $L$ ("Baal is my "fruit"). ${ }^{57}$

Es segura tanto la validez de la ubicación como la reconstrucción del nombre semita y su propio significado en relación con las uvas o las viñas, ya que los griegos conocían el cabo Espartel como Ampelusia, "de las viñas", como recoge Plinio. ${ }^{58}$ Pomponio Mela, ${ }^{59}$ que era natural de la región, nos lo confirma al señalar que si bien los griegos lo llaman Ampelusia, los africanos en su lengua lo llamaban con un término equivalente, por lo que habría que entender que las gentes del país, púnicoparlantes, lo designarían precisamente har 'anbin o har 'anbi.

El har 'anbin o har 'anbi hay que identificarlo pues con el yébel el Quebir, el monte que conforma el promontorio costero del Espartel y que cae en pendiente sobre la bahía de Tánger. ${ }^{60}$ El cabo era conocido entre los fenicios con el nombre de Soloeis

50 Hano 5. Según Gangutia (THA IIA, 33, n. 68), la lectura 'A $\rho$ a 1 ßoús que da Posidonio tiene que ver con la colonia de Arambys.

51 Bochart 1646; Carcopino 1949; Rebuffat 1976, 145-146.

52 Olmo Lete - Sanmartín 1996, 168.

53 Stolz 1978-1985, col. 688.

54 Krahmalkov 2000, 161.

55 En inscripciones arameas aparece también ' $n b y$ ' (plural enfático) “produce in general”, en Nisa- $b$ 812,1

prob. "some produce of the wine” (según HofTIJZER - JONGELING 1995, 874).

56 RebufFat 1976, 150, n. 33.

57 Krahmalkov 2000, 161. LipinsKi $(2004,447)$ considera naturalmente que es un nombre fenicio *har 'anbi y lo traduce directamente como "Mount of the wine".

58 Plin. Nat. Hist. V, 2.

59 Mel. I, 5.

60 Una prueba adicional para identificarlo con el cabo Espartel procede de un portulano griego del siglo XVI en el cual dicho promontorio es denominado Arampe (CARCopino 1949; ReBuffat 1976, 143). 


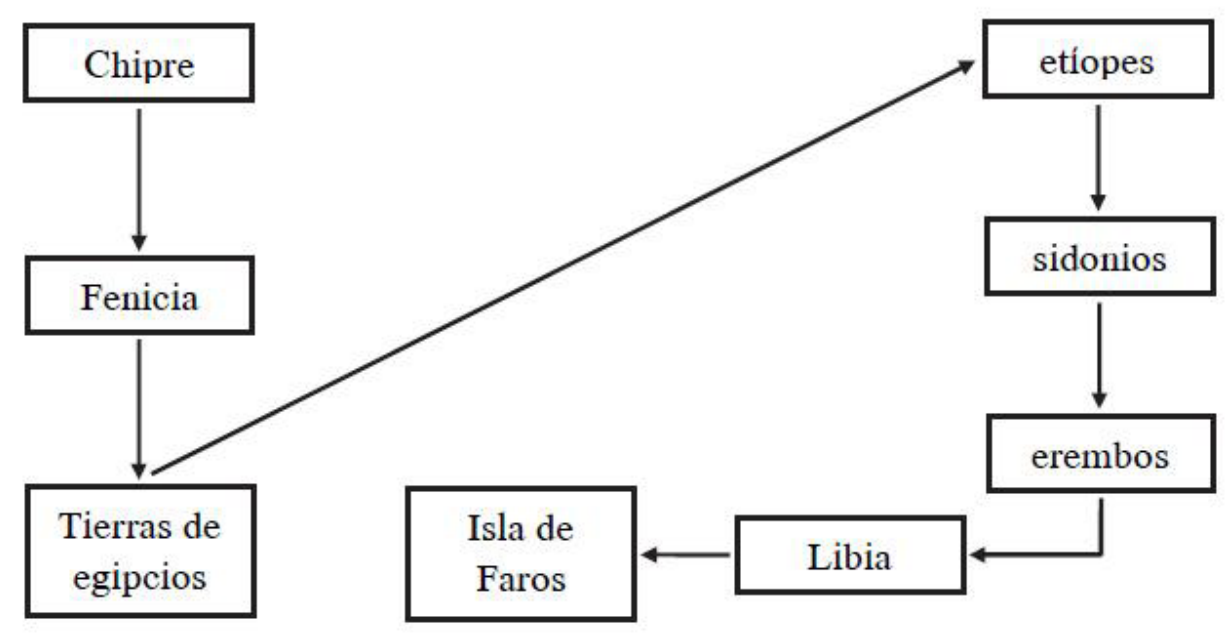

Fig. 1. Esquema del viaje de retorno realizado por Menelao.

(peñón), ${ }^{61}$ señalado como el extremo de África por Heródoto ${ }^{62}$ y por el mismo Periplo de Hanón (Fig. 1). ${ }^{63}$

Cabe pues identificar a los erembos odiseicos con los habitantes del har 'anbin o har 'anbi, los pobladores de la región tangerina de comienzos de la Edad del Hierro, unas gentes que conocemos bien a través de sus necrópolis. ${ }^{64}$ Sus tumbas, de tipología inexistente en el resto de África, son cistas trapezoidales compuestas por grandes placas de piedra, en las que se depositaron inhumaciones individuales o, a lo sumo, dobles, donde los cadáveres aparecen en posición de decúbito lateral flexionado, a veces con restos de ocre rojo como en la necrópolis de Mries. ${ }^{65}$ Este tipo de enterramiento sobre el que se extiende la influencia fenicia y púnica a través de la deposición de ciertos elementos del ajuar funerario y mediante la incorporación de ciertas creencias sobre el Más Allá, ${ }^{66}$ hunde sus raíces en la Edad del Bronce, con claras concomitancias con las tumbas de finales del II milenio a.C. del sur peninsular, con el que mantiene fluidas relaciones la región tingitana, como mostraría el hallazgo

61 Soloeis es un término fenicio común para designar cualquier saliente rocoso, pues su significado es precisamente ése: "peñón" o "saliente rocoso". Soloeis es el nombre semita de una localidad de Sicilia junto a un pequeño cabo, no lejos de Panormos (act. Palermo). También el nombre de la localidad de Sala (Rabat, desembocadura del Bou Regreb) está emparentado con el mismo término.

62 Hdt. II, 32; IV, 43.

63 Según el Periplo (2), después de haber navegado dos días más allá de las Columnas, fundaron una primera ciudad, que llamaron Thymiaterion, a cuyo pie se encontraba una gran llanura. A continuación, siguiendo hacia poniente, llegaron al cabo Soloeis, promontorio de Libya cubierto de árboles. A partir de allí, y según indicación del Periplo, cambiaron el sentido de la navegación en dirección opuesta. El escenario descrito por el Periplo permite afirmar claramente que Thymiaterion corresponde a Tingi, con su amplia llanura, y el cabo Soloeis al Espartel, la punta noroccidental de África, que hoy como en el pasado permanece cubierto de árboles.

64 PonSICH 1967; ID. 1968; ID. 1970, 67-168.

65 JoDIN 1964, 22.

66 López Pardo 1990, 23-26; Kbiri Alaoui 2000. 


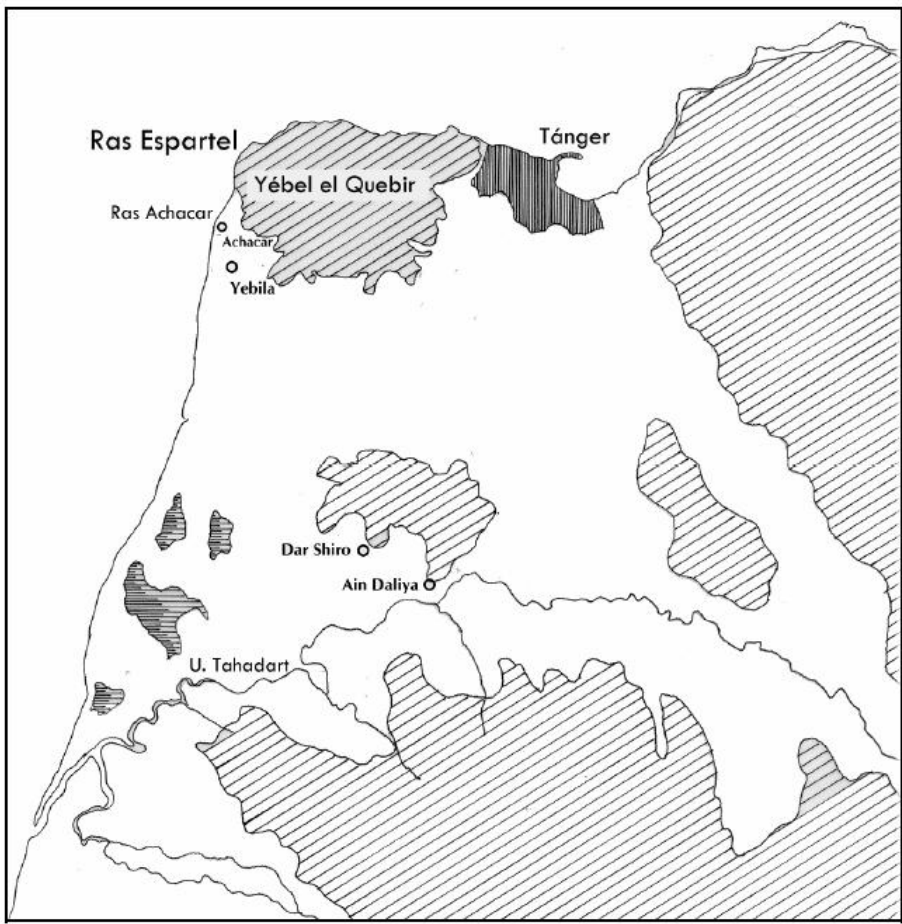

Fig. 2. Región de Tánger. Necrópolis de la I Edad del Hierro.

de algunos objetos metálicos, una punta de flecha en espiga y una pequeña hoja de alabarda de la necrópolis de Mers, seguramente de carácter no utilitario claramente adscrita al tipo Carrapatas. ${ }^{67} \mathrm{La}$ extensión de este tipo de enterramiento no es demasiado amplia, alcanza el río Lucos por el sur y el uadi Lau por el este. ${ }^{68}$ La forma de las tumbas y los objetos metálicos hallados en los ajuares funerarios, permiten asegurar que el grupo cultural tingitano se encuentra especialmente integrado en las relaciones atlántico-mediterráneas y euro-africanas ya desde la segunda mitad del segundo milenio a.C. (Fig. 2). ${ }^{69}$

De todo ello se pueden extraer varias conclusiones. Por un lado, efectivamente parece bastante razonable que los sidonios que menciona después de los etíopes y antes de los erembos tenían una localización occidental, más si cabe por el simple hecho de que poco antes menciona en su recorrido Chipre, Fenicia y los egipcios, por lo que forzosamente deben tener un emplazamiento distinto. Los sidonios se deben identificar en este contexto y por oposición a la mención de Fenicia en el verso anterior con la diáspora tiria o tirio/sidonia del Extremo Occidente. Ello conduce inevitablemente

\footnotetext{
67 Sobre esta pequeña alabarda han tratado: Ponsich 1970, 50 y 55; ONRubia 1988, 162; Souville 1968, 290.

68 Tumba de Alí Thalat (Quintero AtAuri 1940-1941, 563-564.).

69 LÓPEZ PARDo 2000, 17-18.
} 
a considerar que, si bien los testimonios sobre los fenicios en el texto odiseico se pueden inscribir en una amplia horquilla cronológica -ss. XII-VIII a.C.-, la referencia a la presencia estable de los "sidonios" en el Extremo Occidente permite relacionarla con una fecha relativamente baja, más próxima al momento de fijación del poema, ${ }^{70}$ mejor que a la época de la que se evocan los hechos, pues se refiere claramente a un tiempo en el que la colonización fenicia es firme en el Extremo Occidente. ${ }^{71}$ Por otro lado su presencia intercalada entre etíopes y erembos prefigura claramente la costa atlántica de Marruecos colonizada por los fenicios, donde Lixus aparece, como hemos destacado antes, como una fundación especialmente antigua. No obstante, cabe incluir incluso en el imaginado viaje de Menelao a los fenicios situados en la orilla gaditana y onubense, dado que los erembos que visita finalmente se encuentran en la boca oceánica del estrecho. No menos relevante es el hecho de que el etnónimo erembos fuera el calco griego de una denominación semita, lo que permite asegurar que fue a través de la diáspora fenicia del Extremo Occidente como trascendió a la Odisea.

\section{Del har 'anbin a Lixus}

a) ¿Un santuario fenicio en el cabo Espartel?

El Ps.-Escílax ${ }^{72}$ señala la existencia de un altar de Posidón sobre la extremidad del promontorio Soloeis, en un párrafo de difícil lectura en el que C. Müller ${ }^{73}$ lee

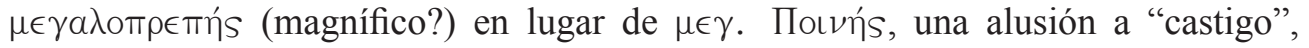
"venganza". ${ }^{74}$ En dicho altar, en cuya descripción se detiene el autor del periplo, aparte de leones y delfines, estaban grabadas efigies humanas. Por su parte, el Periplo

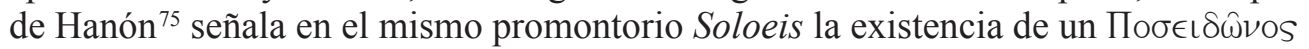
iєৎóv, un lugar sagrado de Posidón, que, como es habitual en el relato, es una más de las numerosas obras del cartaginés. La caracterización histórica de este lugar sacro plantea problemas de toda índole. Empezando por su propia localización, pues hasta el momento presente no se ha hallado ningún vestigio de este supuesto lugar de culto. No es posible localizarlo en la extremidad del cabo Espartel, donde lo sitúa el periplo hanoniano, pues se trata de un lugar de difícil acceso y donde es imposible atracar las naves. ${ }^{76}$ Tampoco es nada fácil insertar estas dos noticias en la realidad cultual de

70 La datación de la obra homérica en el s. VIII está siendo cuestionada por la investigación, y no sólo no se remite en muchos casos al siglo VIII, sino que se apunta a veces a un período posterior: s. VII e incluso el VI (Signes Codoñer (ed.) 2004, 362).

71 Aunque la identificación como sidonios de los habitantes de la costa libanesa sea tanto válida para el final de la Edad del Bronce como para el Hierro antiguo (BeLmonte 2002, 13).

72 Ps. Scyl. 112.

73 GGM I.

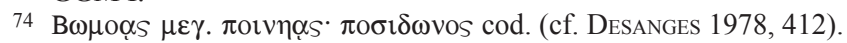

75 Hano 3.

76 El altar habría que buscarlo no en la extremidad del cabo, donde es imposible atracar, sino algo más al sur, cerca de las playas del Ras Achakar-Cotta, donde antaño se localizaron varias tumbas púnicas de cámara de los siglos VI-V a.C. 
la zona en época púnica. Si bien se ha considerado un lugar de culto relacionado con Melqart, ${ }^{77}$ los indicios no dejan de ser enormemente tenues, ${ }^{78}$ lo que nos obligaría a identificar mejor este Posideion o recinto sagrado de Posidón con un santuario dedicado a El o quizás a Baal Hammon, ${ }^{79}$ de alguna manera un lugar de culto comparable en cualquier caso al Krónion de Gades ${ }^{80}$ situado en el extremo más occidental de la isla. ${ }^{81}$

Sin embargo cabría considerar que las referencias del Periplo de Hanón y del Ps.Escílax pueden derivar de la propia recreación de los escenarios relacionados con el mito de Heracles y Anteo. Según algunas referencias mitográficas Anteo forzaba a los extranjeros que pasaban a luchar con él; así construyó un templo a su padre Posidón que adornaba con los despojos de los que había hecho perecer. ${ }^{82} \mathrm{~A}$ este respecto, cabe sospechar que pudo considerarse otro rastro más del episodio de Anteo en la península Tingitana la mención por algunas fuentes de un lugar de culto dedicado a Posidón en estos parajes. En dicho contexto, si es que el recinto sacro de Posidón fue remitido por los tingitanos a dicho pasado mítico, éste habría perdido tras el triunfo de Heracles su anterior consideración de expositor de espeluznantes ofrendas, transformándose en el "discreto" lugar de culto que el Ps.-Escílax y el Periplo de Hanón describen justo a continuación de Thymiateria/Thymiaterion, Tingi si seguimos a éste último. ${ }^{83}$

\section{b) Las fundaciones de Hanón}

Con renovado interés vemos hoy la información reportada por el Periplo de Hanón ${ }^{84}$ sobre los nombres de los enclaves coloniales que supuestamente fundó el cartaginés una vez que levaron anclas en una laguna próxima al cabo Espartel y antes de llegar al gran río Lixos (Lucos). Aunque hoy en día no estamos en disposición de confirmar o no el carácter hanoniano de las fundaciones, pues pueden ser anteriores y deberse a una dinámica de ocupación generada en la misma zona, la revisión reciente de los topónimos permite asegurar su origen genuinamente fenicio-púnico, menos alterados por la edición griega del periplo de lo que se pensaba hasta ahora. Los enclaves mencionados en el Periplo son Karikon Teichos, Guttē, Akra, Melitta y Arambys, y

77 LIPINSKI 1995, 120 y 233, n. 85; ID. 2004, 427-428.

78 Sólo ha podido argumentarse una hipotética asimilación en Larnaka-tes-Lapethou (Chipre) de Posidón Narnakios con Melqart bnrnk, que sería excepcional en el caso de ser veraz frente a la masivamente generalizada identificación de Melqart con Heracles (BONNET 1988, passim).

79 Posidón es identificado como el dios El en una inscripción bilingüe de Palmira (LIPINSKI 1995, 60). Por otro lado "El, poseedor/creador de la tierra" aparece en epigrafía latina de Leptis Magna como un Neptuno púnico (Levi della VitTa - Amadasi Guzzo 1987 [1927-1967], nº 30 [36] y nº 18 [13]). El nombre semítico de la localidad de Posideion (Ras el Bassit) era Butullivov, es decir Bt-'l, (LipInski 1995, 119). Y en Beirut, la deidad principal es identificada por Filón de Biblos (Eus. PE I, 10, 35) como Posidón.

80 Str. III, 5, 3.

81 Ruiz Mata (1999, 300-301) entiende que Crono en Grecia tuvo escasa entidad cultual y es probable que el Krónion gaditano no estuviese representado por un templo, sino por un espacio o punto geográfico destacado y su importancia residiese en el culto y en sus connotaciones funerarias.

82 PI. I, IV, 70 y ss.; Apollod. II, 5.

83 López PARdo 2005a.

84 Hano 5. 


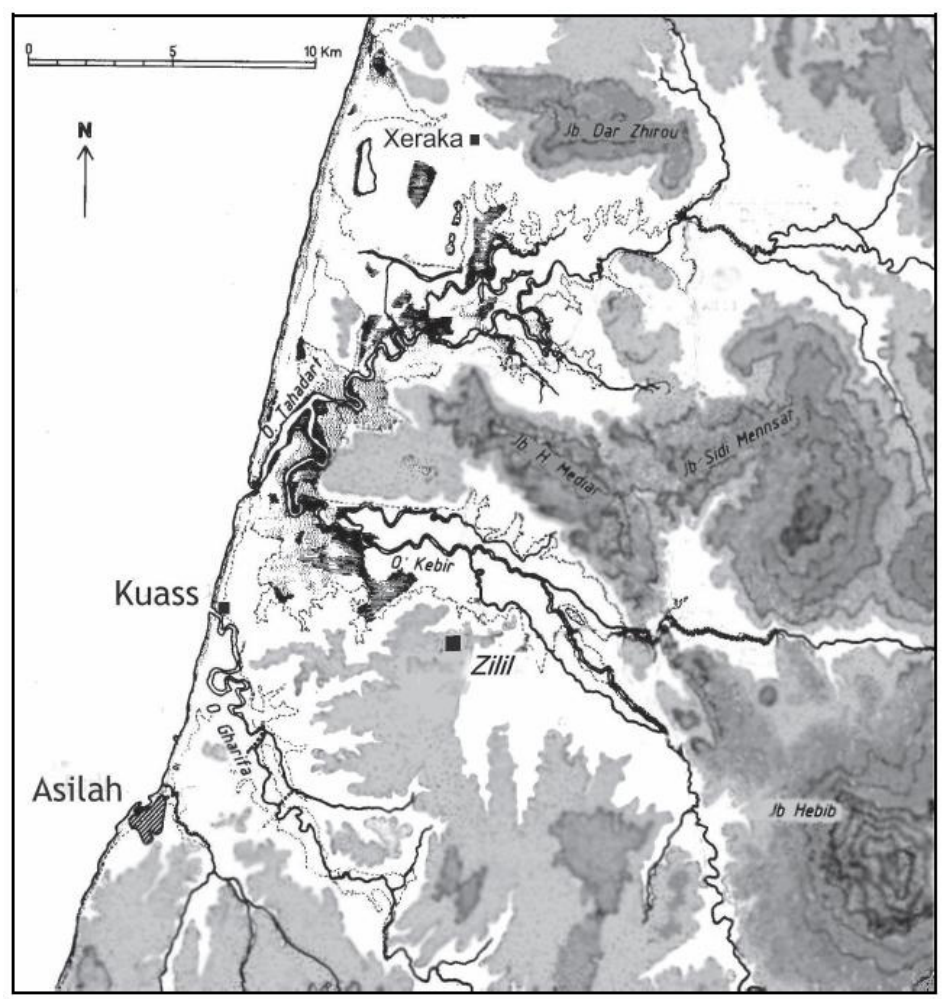

Fig. 3. Región del U. Tahadart.

los ordenaremos de norte a sur según los indicios con los que contamos para su ubicación, entendiendo que el Periplo los presenta desordenados (Fig. 3).

Arambys, se encontraría naturalmente en el entorno del cabo Espartel, como hemos señalado páginas atrás. Próxima a Arambys o al "monte de las uvas" podría encontrarse Guttē, si tenemos en cuenta que en fenicio *Gitt significa "prensa de vino" o "prensa de aceite" ${ }^{85}$ pareciendo existir una relación funcional o simbólica entre ambos topónimos. ${ }^{86}$ Deberíamos identificar quizás Arambys y/o Guttē, con los restos arqueológicos próximos al fondeadero del cabo Achakar y de la colina de Djebila. ${ }^{87}$ En esta última se han hallado ánforas fenicias y púnicas ${ }^{88} \mathrm{y}$ al pie de la colina aparecieron unos fragmentos de cerámica griega, entre ellas una crátera laconia del s. VI a.C. y una copa ática de figuras negras del 500-490 a.C. ${ }^{89}$ En relación con el pobla-

85 LIPINSKI 1992; ID. 2004, 454.

86 Aunque la relación no es segura, pues puede tener un significado más amplio, como explotación agrícola o hacienda. Cf. gt en ugarítico y gittu en acadio de Tell el Amarna, donde además de trujal o lagar tiene el sentido de alquería, Olmo Lete - Sanmartín 1996, 152.

87 Sin embargo, LiPInSKI $(2004,454)$ prefiere identificar Guttē con Dchar Djedid o Kuass. Cuando la primera ya ha provisto evidencias de tratarse de la antigua Zilil.

88 Ponsich 1964, 266.

89 Villard 1960, 12-14; Ponsich 1967, 185. 
miento de esta zona se hallan tanto la necrópolis de tradición indígena con influencia púnica aledaña al hábitat de Djebila como la más alejada necrópolis de cámaras del Ras Achakar. ${ }^{90}$

Algo más al sur se encuentra la desembocadura del río Tahadart, el cual conserva en la actualidad una extensa planicie inundada en algunas épocas del año, vestigio de un antiguo gran lago, abierto al mar según los resultados de los sondeos paleoambientales realizados. ${ }^{91}$ Este amplio estuario abierto a la influencia marina debía ser el que Mela ${ }^{92}$ llama Gna y Tolomeo ${ }^{93}$ Agna, situado según el primero entre la colonia (Zilis) y el cabo Ampelusia. De nuevo la denominación nos parece de origen fenicio-púnico, pues se constata epigráficamente ' $g n$ referido a recipientes para contener líquidos, ${ }^{94}$ y en ugarítico agn se usa también para "estanque". ${ }^{95}$ Este último significado es el que cabría atribuir a la denominación fenicio-púnica del golfo estuarino del Tahadart, ${ }^{96} \mathrm{en}$ cuyos bordes se debían disponer distintas fundaciones fenicio-púnicas.

Volviendo de nuevo a las localidades mencionadas en el Periplo de Hanón, pero sin salir seguramente de esta formación lagunar del 'gn/Tahadart, hemos de mencionar Karikon Teichos, que ya en solitario Blázquez y Delgado-Aguilera ${ }^{97}$ relacionara con el lugar moderno de Xeraka, precisamente en el fondo norte de este antiguo lago. La aproximación adquiere mayor verosimilitud desde el momento en que podemos situar los otros enclaves mencionados por el Periplo en este contexto espacial y por la nueva lectura que realizamos del topónimo. ${ }^{98}$ Los griegos ya desde el siglo IV a.C. al menos habían dado a Karikon Teichos el sentido de "fuerte cario"99 y así se mantiene en el manuscrito griego del Periplo de Hanón, pero nosotros entendemos que se trata de una simple interpretatio graeca, pues teichos ("fuerte", "fortificación") es una traducción en griego de $k r k,{ }^{100}$ término ampliamente documentado en lenguas semíticas con el mismo sentido de "fortificación", "recinto fortificado", "ciudad fortificada", ${ }^{101}$ con lo que el auténtico nombre de la localidad fenicio-púnica era éste, $k r k .{ }^{102}$

El golfo encontraba su límite sur en el promontorio de Ras al Kuass que lo separa de la desembocadura del propio río Kuass. Precisamente en una terraza de este saliente se encuentran las ruinas excavadas de un hábitat prerromano con restos arqueológicos bien datados en pleno s. VI a.C., pero con posibilidades de que algunos

90 Ponsich 1967.

91 Ballouche 1986, 63.

92 Mel. III, 10.

93 Ptol. IV, 2.

94 Krahmalkov 2000, 31.

95 Olmo Lete - Sanmartín 1996, 13.

96 Quizás también sea el río Anides mencionado por el Ps.-Escílax (112), que se encuentra entre el cabo Hermeo y el Lixos, el cual desemboca en un gran lago.

97 Blázquez y Delgado Aguilera 1921, 415.

98 López Pardo - Mederos Martín - Ruiz Cabrero 2007. De forma independiente ha llegado a una conclusión similar FANTAR (2002) al relacionar Karikon con $Q r$, que tiene un significado parecido.

99 Ephor. Fr-GrHist 70 F 53.

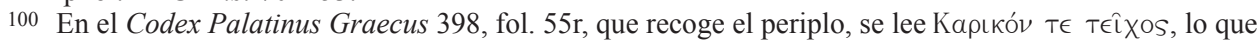
parece apuntar ya que el segundo término traduce el topónimo fenicio.

101 HoftiJzer - Jongeling 1995, 535-536; KRAHMALKov 2000, 241

102 Menos probable me parece la propuesta de LIPINSKI (2004) que relaciona Karikon con el líbicobereber i-kerkar, "big stones" y kkerker "to wall oneself up". 
sean incluso anteriores. El enclave fenicio llegó a contar después con un destacado centro alfarero dedicado especialmente a la manufactura de ánforas ${ }^{103}$ destinadas fundamentalmente al envasado de salazones de pescado. ${ }^{104}$ Sus talleres cerámicos también abastecían de vasos de uso funerario a las poblaciones indígenas asentadas en la región tangerina, ${ }^{105}$ que en parte se seguían enterrando con rituales propios de la tradición de la Edad del Bronce. De entre los nombres recogidos por el Periplo de Hanón podríamos atribuir a este asentamiento del Ras al Kuass el de "Aкра, nombre que tiene su correspondiente en el término fenicio $R o$ 'š, de idéntico significado. Sobre este sitio, E. Lipinski propone denominarlo *Ro'š Sakkōn, al entender que el Sakon fenicio se identifica con Hermes/Mercurio. ${ }^{106}$ Sería pues la 'Epraía åkpa del Ps.-Escílax, ${ }^{107}$ pero no es seguro siquiera que 'Epraía haga referencia directa a Hermes. Por lo que nos deberemos contentar por el momento con la idea de una referencia fenicio-púnica a un promontorio cuya denominación no conservamos.

A pocos kilómetros al este de Kuass y en el mismo contexto espacial se encuentra el yacimiento de Dchar Jdid, donde se ha documentado una ocupación prerromana ${ }^{108}$ que parece remontar al menos a la segunda mitad del siglo IV a.C. ${ }^{109}$ Su nombre antiguo era Zilil, como consta en inscripciones halladas in situ, y a esta localidad refundada por Augusto se refieren algunos autores antiguos que mencionan el traslado de sus antiguos residentes al otro lado del Estrecho. La búsqueda del origen del nombre nos ha llevado a relacionarlo con el sustantivo fenicio-púnico țll, "protección", ${ }^{110}$ que se documenta en otras lenguas semitas, entre ellas en ugarítico, donde aparecen las formas $z l l \mathrm{y} z l .{ }^{111} \mathrm{El}$ significado conviene al lugar donde han aparecido los restos arqueológicos prerromanos, el lugar alto y escarpado conocido por los excavadores como "La citadelle" (Fig. 4).

Completa el panorama de fundaciones trazado en el Periplo de Hanón, antes de que las naves del cartaginés llegaran al estuario del Lixos, el asentamiento mencionado en el documento con el nombre de Melitta, quizás una confusión o asimilación intencionada entre Melitta $<$ Šelitta que debería identificarse con la localidad reconocida por acuñaciones monetales de 'šlyt, topónimo púnico que significaría "red" o "pesquería". ${ }^{112}$ Aunque 'šlyt se ha identificado frecuentemente con Zilil, ${ }^{113}$ parece altamente improbable, pues no presenta ninguna similitud fonética, aparte de ser este

103 PONSICH 1968.

104 López PARdo 1990, 23. Una revisión a fondo de las antiguas excavaciones y un estudio sistemático de los materiales de Kuass han sido realizados por Mohamed Kbiri Alaoui en su tesis doctoral recientemente publicada (Kbiri Alaoui 2007).

105 Kbiri Alaoui 2007.

106 LIPINSKI 1995, 177; ID. 2004, 453.

107 Ps. Scyl. 112.

108 AKERRAZ ET ALII 1981-1982.

109 López PARDo 1990a.

110 Cf. HoftizJer - Jongeling 1995, II, 423.

111 Olmo Lete - Sanmartín 1996, 551-552. En esta última vemos la pérdida de la consonante duplicada, un fenómeno común en lenguas semitas. Este hecho se repite en el nombre de Zilil (Zulil en Plin. Nat. Hist. V, 2), como recogen algunas fuentes: Zelis (Str. III, 1, 8; XVII, 3, 16), Zili (Itin. Anton. Aug. III).

112 Mazard 1955; Le Glay 1992.

113 Últimamente LIPINSKI 2004, 450-451. 


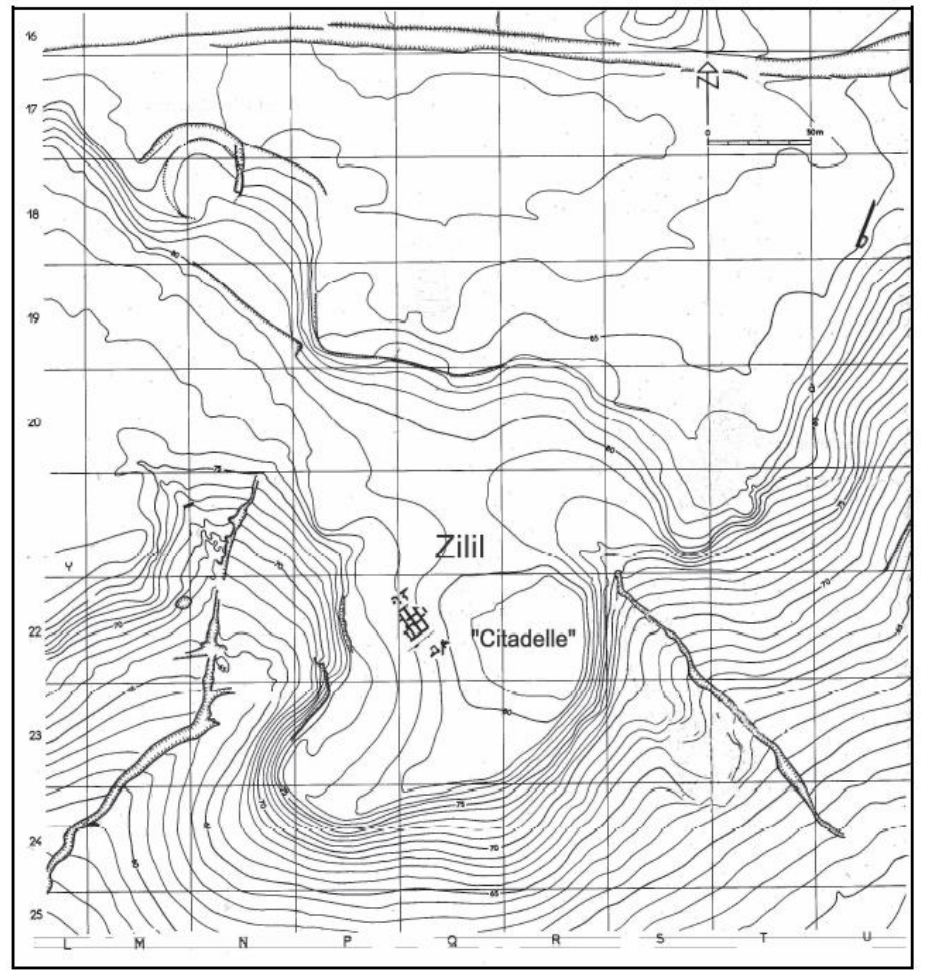

Fig. 4. Zilil , según A. Akerraz et allii (1981-1982): "Fouilles de Dchar Jdid, 1977-1980”, BAM 14, 1981-1982, 169-244.

último también un nombre de filiación fenicio-púnica, como hemos visto. Sería posible sugerir Asilah (Arcila), que se encuentra unos kilómetros más al sur sobre la costa, la cual habría conservado el topónimo antiguo. La localidad cuenta con un puerto aceptable para pequeñas embarcaciones pesqueras, como vemos en dibujos del s. XVI.

\section{c) El golfo empórico (Kolpos emporikos)}

Según una información recogida por Estrabón ${ }^{114}$ y seguramente transmitida antes por Ofelas y Eratóstenes, en estos lugares se encontraba un golfo llamado "empórico" que albergaba establecimientos comerciales fenicios. Aunque frecuentemente se ha imaginado al sur del Lucos, algunos indicios hacen sospechar que las antiguas fuentes de Estrabón se estaban refiriendo a la costa comprendida entre el cabo Espartel y el estuario del Lucos inclusive. Nos lo confirma el propio Estrabón cuando dice que en el Kolpos emporikos se encuentra un antro con un terreno bajo y unido donde se

114 Str. XVII, 3, 2. 
eleva un altar de Heracles, que jamás recubre el flujo, ${ }^{115}$ escenario al que alude Plinio situándolo en el estuario del Lucos. ${ }^{116}$

Así pues, la franja costera que incluía las formaciones estuarinas del Tahadart y del Lixos se configura como ámbito de actividades empóricas, de comercio intenso para los fenicios y posiblemente para los griegos en las fechas de la arcaica fuente de Estrabón (s. V a.C.?). Quizás la denominación, procedente seguramente del Periplo de Ofelas, fuera acuñada por mercaderes griegos que tenían designados estos puertos para sus transacciones en la costa atlántica africana. El texto subraya que los enclaves eran mantenidos por los fenicios, cuya actividad debía centrarse en el intercambio con los indígenas, generando un acopio de materias a las que podían acceder distintas entidades comerciales griegas, de ahí el interés de calificar este golfo como emporikos (comercial).

\section{Al sur de Lixus}

En ese momento antiguo al que se refiere Estrabón (s. V a.C.?), aparentemente los griegos no podían ir más al sur para cerrar transacciones comerciales, no porque los numerosos establecimientos tirios que se encontraban más allá de este golfo son llamados coloniales en vez de distinguirlos como factorías, sino porque se hallaban abandonados al haber sido destruidos por poblaciones indígenas especialmente belicosas, los Nigritae y Pharusii. ${ }^{117}$ No es posible, por el momento, saber cuál fue el alcance de las destrucciones, pero la noticia pone en evidencia la existencia de numerosos enclaves fenicio-púnicos más allá del Lucos, de los cuales la investigación arqueológica ha mostrado un rastro muy reducido.

El frecuente trasiego naval entre Lixus y la desembocadura del Sebú, el gran cauce fluvial del Marruecos atlántico, permitió sin duda codificar uno de los promontorios de esta línea costera con el nombre de Melqart ( $R$ 'š Mlqrt), nombre conservado en un portulano de origen medieval que cita el Rasmikar. ${ }^{118}$ Encontramos una confirmación en el geógrafo Tolomeo, ${ }^{119}$ que sitúa en estas latitudes el Promontorio de Heracles, el héroe griego con el que habitualmente se asimila al dios fenicio. La consagración al dios tirio del promontorio encuentra su homónimo $R$ 'š Mlqrt en la costa septentrional de Sicilia, un cabo que da nombre a un enclave o santuario próximo que acuña moneda en época púnica con esta leyenda. ${ }^{120}$

Un primer abrigo portuario se encontraba en Moulay Bouselham, que da acceso a una zona de marisma que antiguamente sirvió para el atraque de barcos. Este lugar era conocido en los portulanos medievales con el nombre de Mosmar, Mismar, etc.,

115 Str. XVII, 3, 3.

116 Plin. Nat. Hist. V, 2-4.

117 Str. XVII, 3, 3 y 8.

118 Rebuffat 1976, 149, n. 8.

119 Ptol. IV, 2.

120 Manfredi 1985, 3-8. 


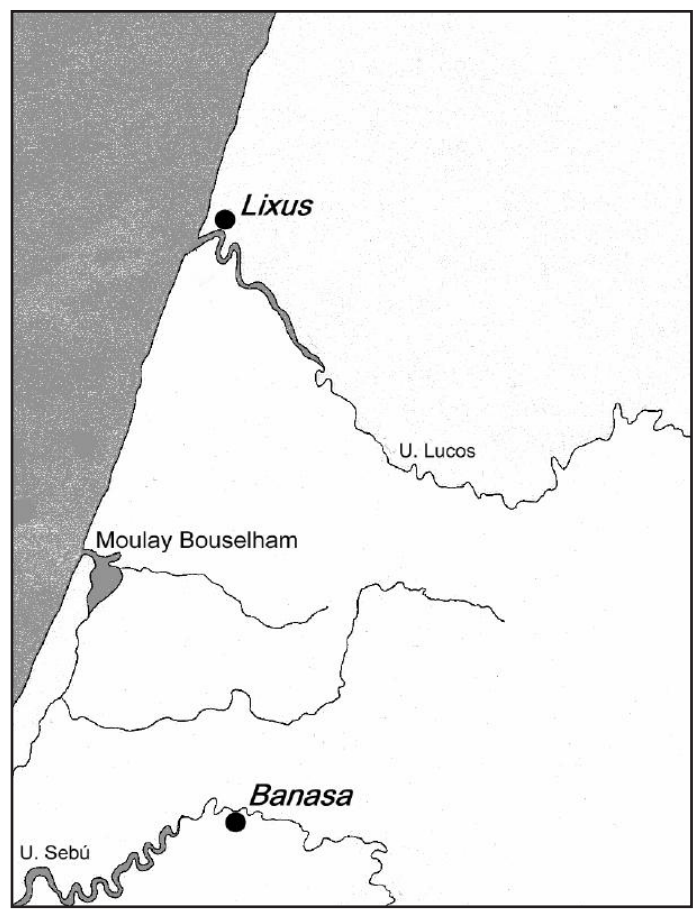

Fig. 5. De Lixus al U. Sebú.

cuyo significado en fenicio-púnico es "abrigo", "lugar protegido", ${ }^{121}$ lo que se adecua a sus excelentes condiciones de refugio para los barcos (Fig. 5).

El uadi Sebú, la gran vía natural de penetración de la llanura del Gharb, descrito como "magnificus et navigabilis" por Plinio, ${ }^{122}$ era transitado por las naves fenicias que recorrían sus sinuosos meandros hasta la antigua localidad de Banasa, a $80 \mathrm{~km}$ de la desembocadura. El nombre antiguo del río, Sububus según Plinio, ${ }^{123}$ creemos que procede de la voz fenicia $s b b$ "dar vueltas", "girar", ${ }^{124}$ muy apropiado para aludir a los inmensos meandros que describe el río desde su curso medio hasta el mar. Cerca del estuario se encuentra Thamusida, localidad de importante florecimiento en época mauritana ${ }^{125}$ que parece arrojar evidencias de una ocupación fenicia arcaica. Esta cuenca fluvial, seguramente de gran interés económico para los fenicios, contaba con un asentamiento a término para las naves en Banasa, un excelente vado para cruzar el río donde algunos sondeos arqueológicos sacaron a la luz algunos alfares en los que se manufacturaron cerámicas de tradición local y se imitaron formas importadas que

121 Cf. Krahmalkov 2000, 318.

122 Plin. Nat. Hist. V, 1, 5.

123 Plin. Nat. Hist. V, 5 y 9.

124 Véase HoftiJzer - Jongeling (1995, 772-774) donde se recoge también su existencia en hebreo, amonita y arameo. En ugarítico $s-b-b$ (Olmo Lete - SANMARTín 1996, 397).

125 Rebuffat - Hallier - Marion 1970, 16. 


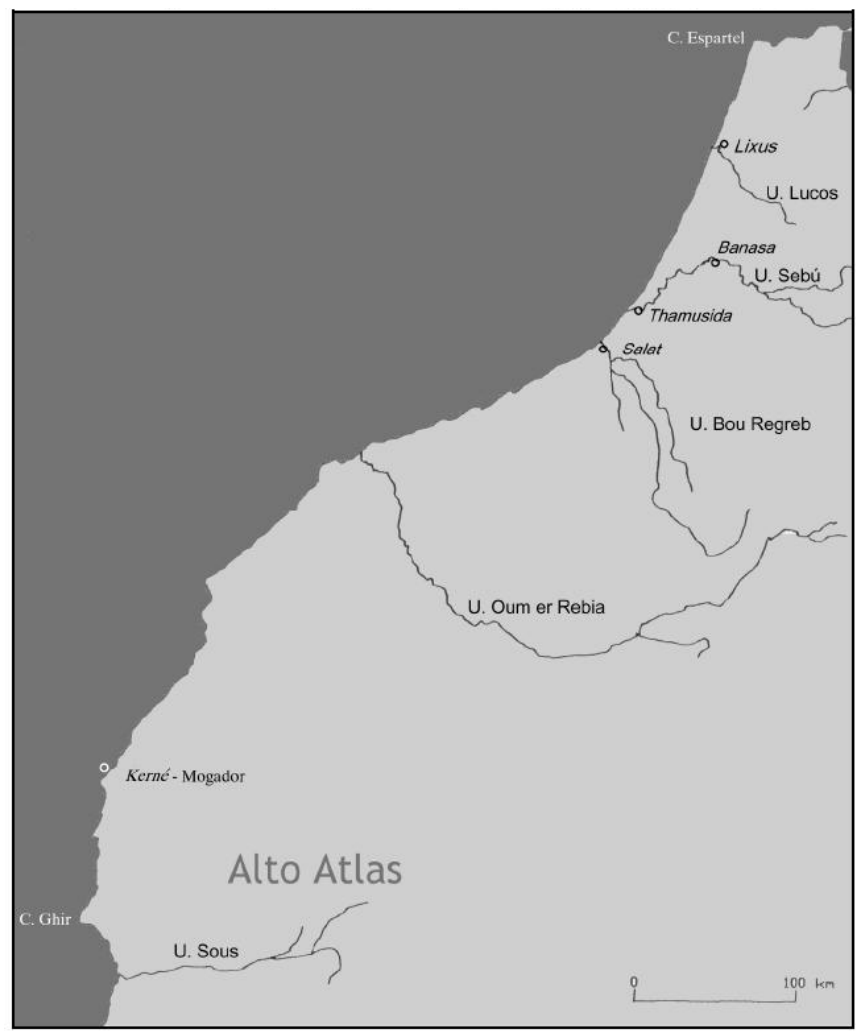

Fig. 6. Marruecos atlántico.

llegaron con fluidez al enclave. Se pueden datar sus orígenes en una fecha anterior a mediados del s. VI a.C., pues se han hallado algunas ánforas fenicias Rachgoun 1 y una lucerna ática del tipo Howland $23 \mathrm{~A} .{ }^{126}$

El siguiente cauce fluvial de cierta envergadura es el Bou Regreb, en cuya desembocadura se encontraba Sala o Salat ${ }^{127}$ (Fig. 6). Su nombre fenicio, S'lt / Salat, es una forma femenina de *Sl' y corresponde al significado de "peñasco". ${ }^{28}$ Quizás el nombre se refiere al saliente berroqueño de la Casbah de los Oudaias (Rabat), en el mismo estuario donde se encontraron cerámicas fenicias o púnicas. ${ }^{129}$ No obstante, los restos de la ciudad púnicomauritana y después romana se encuentran en la siguiente curva del río, a unos tres kilómetros, en el recinto de la necrópolis meriní de

\footnotetext{
126 Noticia recogida por Aranegui Gascó - Kbiri Alaoui - Vives-Ferrándiz Sánchez 2004.

127 Plin. Nat. Hist. V, 9 y 13.

128 LIPINSKI 1992.

129 Luquet 1973-1975, 261; Ponsich 1982.
} 
Chellah (Šella), que parece haber conservado el nombre antiguo, ${ }^{130}$ donde se hallaron algunos fragmentos de cerámica de engobe rojo quizá arcaica. ${ }^{131}$

Desde la desembocadura del Bou Regreb hasta el cabo Ghir, allí donde las estribaciones del Alto Atlas se asoman al mar, la costa es poco hospitalaria y apenas ofrece abrigos naturales para la navegación. Sólo las desembocaduras de los ríos siguen siendo refugio seguro cuando la barra no hace impracticable el paso de entrada. ${ }^{132}$ Precisamente los periplos antiguos se vuelven especialmente oscuros y escasos de información al describirnos este tramo, y a pesar de ser una zona repetidamente prospectada, poco es lo que se ha señalado como prerromano. ${ }^{133}$ De Azenmour, junto a la desembocadura del Oumm er Rebia, P. Cintas notificó el hallazgo de fragmentos de cerámica púnica. ${ }^{134}$

\section{La isla de Mogador: de qrn (Kérnēe a Mogdoul}

El viajero medieval El-Bekri ${ }^{135}$ ya señaló que Mogdoul (actual Essaouira) era un fondeadero muy seguro, sin duda gracias a la protección contra el oleaje que le brindaba la isla de Mogador y el saliente rocoso donde se asienta la localidad actual. Un asentamiento fenicio surgió en la isla en la primera mitad del siglo VII a.C. subsistiendo algo más de cien años; éste se localiza en la costa oriental, la que da al continente y la más resguardada de los fuertes vientos que soplan del noroeste (Fig. 6). La ausencia de muros entre los vestigios fenicios ya hizo sospechar a A. Jodin ${ }^{136}$ que se trataba de una factoría estacional, extremo que puede confirmarse a través de la cultura material exhumada. La falta de talleres alfareros, propia de un asentamiento temporal, hizo que los residentes repararan con frecuencia los platos y cuencos rotos y, ante la imposibilidad de adquirir o reparar las lámparas de aceite, las reproducían rudimentariamente. También es significativa a este respecto la profusión de graffiti grabados en la vajilla de mesa y las ánforas, según veremos más adelante. Distintos indicios denotan que un alto porcentaje de los recipientes cerámicos hallados en Mogador procedía de un mismo taller foráneo, que con toda probabilidad se encontraba en la bahía gaditana. ${ }^{137}$ Sería sugerente pensar en Castillo de Dña. Blanca, que tantos paralelos nos ha aportado, para proponer Gadir como el lugar de procedencia de estos productos. Sin embargo, las ánforas fenicias occidentales (R1) halladas en el yacimiento presentan una variedad de pastas y engobes realmente notable que denotan una gran diversidad de procedencias, entre ellas hemos podido identificar algunas originarias de la costa malagueña, de la bahía de Cádiz y de Lixus, lo que denota que en el abastecimiento de

130 LIPINSKI 1992.

131 Boube 1981, 166-168.

132 Despois - Raynal 1967, 266-267; LuQuet 1973-1975, 297.

133 LuQuet 1956; RebufFat 1974.

134 Cintas 1954, 24; LuQuet 1973-1975, 270, fig. 21.

135 El BeKri 1911-1913, 175.

136 JODIN 1966, 52.

137 Kbiri Alaoui - López Pardo 1998; López Pardo - Habibi 2001; con más indicios y argumentos López PARdo - Ruiz CABRERo 2006. 
vino, aceite y conservas Mogador dependía de un centro redistribuidor gaditano que también se ocupaba de hacerle llegar vino y aceite de Grecia y de Chipre.

La parte conocida de la factoría fue abandonada a mediados del s. VI a.C. y no sabemos si ello significa que la ensenada dejó de frecuentarse con la intensidad que lo había sido hasta ese momento o que el lugar de residencia se desplazó a otro punto en la propia isla o en el continente. Quizás el abandono tuviera que ver con la desolación desatada por los etíopes Nigritae y Pharusii que recoge Estrabón de una fuente antigua, pero la indefinición cronológica de estos hechos impide un acercamiento preciso a la cuestión. El hecho es que la estratigrafía del yacimiento muestra antes de la intensa ocupación de época de Juba II algunos restos de ánforas de la región del estrecho que van del siglo V al III a.C. y huesos de elefante que indican una actividad humana de carácter esporádico o marginal en este sector tras su abandono. ${ }^{138}$

La localidad de Mogador, actual Essaouira (enfrente de la isla), era conocida en textos árabes del siglo XI con el nombre de Amogdoul y precisamente junto a la desembocadura del río Ksob, frente a la isla, se encuentra el morabito de un santón musulmán que recibe el nombre de Sidi Mogdoul. Como recoge Stumme, ${ }^{139} \mathrm{mogdul}$ es un término que aparece en fenicio y púnico con el significado de "torre", documentado desde el segundo milenio a.C. ${ }^{140}$ Con el tiempo Mogdoul se transformó en Mogdura para los portugueses y en Mogadur para los españoles. ${ }^{141}$

El Anónimo de Rávena recoge de fuentes romanas del Alto Imperio el nombre del puesto denominado Turris Buconis. ${ }^{142}$ Tolomeo ${ }^{143}$ sabe del mismo enclave y lo transcribe en griego como Boccanon Hemeroscopeion (atalaya), casi al final de una ruta caravanera jalonada por unos pocos puestos que comunicaba Volubilis con el valle del Sous y la costa, precisamente en las inmediaciones de Mogador. Sin duda turris y hemeroscopeion son el trasunto del púnico magdal/mogdul, nombre con el que se conocía en época prerromana el lugar.

Lo que nos parece más destacable de los nombres recogidos por Tolomeo y el Anónimo de Rávena y lo que justifica este pequeño excursus, es que el segundo componente del nombre, Buconis/Buceron, es la traducción latina de qrn "cornamenta" en lenguas semitas, nombre transcrito en griego de forma casi literal como Kérnē. Así nos parece claro que el nombre púnico era Mgdl qrnm, es decir "Torre de los (dos) cuernos", o bien Mgdl qrn "Torre de la cornamenta", en cualquiera de las cuales está implícita la referencia a la isla de Mogador como Kérnē por su semejanza con una gran cornamenta como hemos podido comprobar sobre el terreno y a través de la cartografía. También es de interés comprobar que aún en época romana los pobladores

138 Jodin 1957; López PARdo 2001, 228.

139 STUMMe 1912, 123-124.

140 Olmo Lete 1981, 574. El topónimo lo encontramos en el sur de Fenicia y correspondería al nombre de diferentes plazas fuertes o torres fortificadas (Ej. Migdal El [Io. 19, 37-39], Migdol [Ez. 14, 1-2]).

141 LIPINSKI 1994, 126; ID. 2000, 285.

142 El Geógrafo de Rávena $(164,9)$ cita Perora, justo antes Getulidare, Turris Buconis, Paurisi, y poco después una Mauritania Perosis al sur de la Tingitana (166, 7-8). Según Desanges (1962, 233) esta última parece hacer referencia a una Mauritania de los Pharusii. La relación de Turris Buconis con la Mauritania de los Pharusii (de los que hablaremos más adelante) permite adelantar la identificación con Mogador.

143 Ptol. IV, 7. 
de raigambre púnica de la zona seguían comprendiendo el significado primigenio del nombre de la isla de Kérnē /Mogador, es decir, el referido a su aspecto de cornamenta.

\section{Los Pharusii, conductores de carros}

Siguiendo a Tolomeo ${ }^{144}$ habría que situar este pueblo en las proximidades del Oum er Rbia o el Tensift, según cuál se identifique con el río Anatis, pues el geógrafo llama

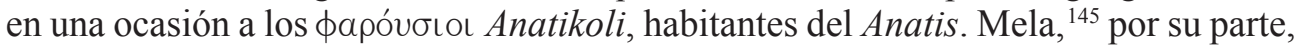
sitúa a Nigritae y Pharusii más allá de los Mauri, y después nos dice ${ }^{146}$ que sus orillas son ricas en púrpura, lo que podría indicar su proximidad a las islas Purpurarias de Juba II, localizables en Mogador. ${ }^{147}$ Una concreción geográfica que permite aceptar la indicación de Tolomeo de su posición ribereña en torno al Anatis si se trata del Tensift, que fluye por la llanura de Marrakech y desemboca relativamente cerca de Mogador. En época de Estrabón su territorio se encontraría en la vertiente sur del Atlas, entre el Draa y el Guir, lo que les permitiría alcanzar el Alto Muluya y dirigirse a los chotts de Cirta en Argelia. ${ }^{148}$

La extraordinaria movilidad que les proporcionaban sus carros es indirectamente destacada por Estrabón, ${ }^{149}$ pues según el autor los Pharusii se encuentran a veces con los Maurousioi, localizados al norte, hacen travesías del desierto colocando odres de agua bajo los caballos y llegan ocasionalmente hasta Cirta, en Argelia, atravesando marismas y lagos (los chotts argelinos). ${ }^{150}$ También su capacidad para recorrer rápidamente la costa les habría permitido destruir numerosos establecimientos tirios al sur del golfo Empórico, según una fuente antigua que recoge Estrabón, al tiempo que se refiere al periplo de un desconocido Ofelas. ${ }^{151}$ De forma aparentemente exagerada se cuantifica las destrucciones en número de trescientas, pero que con mucha probabilidad se trata de una fórmula fenicia para señalar una gran cantidad. ${ }^{152}$ Lo cual nos indicaría que la fuente de información antigua a la que se refiere Estrabón, quizás recogida por este misterioso Ofelas, era fenicia. Ello nos permite relacionar el nombre de los Pharusii no con una denominación indígena propia o una asimilación

144 Ptol. IV, 6, 6.

145 Mel. I, 22.

146 Mel. III, 104.

147 Ello explicaría que poco después los localice entre las Hespérides y el Atlas (Mel. III, 105).

148 Desanges 1962, 232.

149 Str. XVII, $3,7$.

150 Sobre los Pharusii véase el análisis exhaustivo de Desanges 1962, 230-232.

151 Str. XVII, 3, 3.

152 Una fórmula, 30, 300, 3000, 30.000, que se repite con las tres miríadas de hombres y mujeres que son transportadas en las naves de Hanón para colonizar la costa atlántica africana (Peripl. 1), pues la cifra de 30.000 aparece a continuación del término $\pi \lambda \hat{\eta} \theta$ os "muchedumbre", "multitud", lo que sugiere que la cifra estuvo en el texto original y que en realidad se trataba de una cantidad expresiva de gran número (LÓPEZ PARDO 2008). En cuanto a esta cantidad E. Lipinski, por su parte, propone también un origen semita, pues $\mu u p ı a ́ s$, "diez mil", "cantidad sin número", se corresponde con el hebreo rbbh, que originalmente designaba algo en gran número, equiparable con diez mil, el número tres o triple, que es la calificación semítica de la perfección y la eficiencia (LIPINSKI 2004, 444). 
a los persas que parece realizada a posteriori y con fines mitográficos, ${ }^{153}$ sino más bien con un término fenicio referido a la conducción de carros, pues en hebreo bíblico se presenta paraš, "jinete", "conductor de carro" 154 y en ugarítico prs (I) n.m. es "una pieza del carro". ${ }^{155}$ Ello explicaría la caracterización de estos etíopes como diestros aurigas y su asombrosa movilidad por parte de Estrabón, como acabamos de mostrar.

Estaríamos también ante un episodio histórico antiguo, la destrucción de factorías fenicias por parte de dos pueblos, Nigritae y Pharusii según Estrabón, o mejor ante uno solo, teniendo en cuenta que Pharusii nos parece un epíteto con el sentido de "conductores de carros". Podría abundar en ello el hecho que Estrabón los menciona juntos, dice que tanto unos como otros están armados de arcos y que ambos se sirven de carros. Además la precisión que hace Plinio al considerar que los Nigritae y los Pharusii son etíopes, ${ }^{156}$ nos lleva finalmente a considerar que seguramente estamos ante una referencia fenicia antigua a "etíopes conductores de carros", que tardíamente podemos encontrar aún en la referencia del mismo Plinio ${ }^{157}$ a los etíopes Perorsi que según el autor tocan el Océano en el límite de la Mauritania. ${ }^{158}$

Tampoco sería banal a este propósito la mención a los Khouritae, pueblo únicamente mencionado por Tolomeo, ${ }^{159}$ que considera precisamente vecinos de los Pharousii, extendiéndose en dirección al monte Kaphas, de donde el Daras (Draa) nace. Creemos que puede ser una corrupción de Khousitae, pues Tolomeo menciona la des-

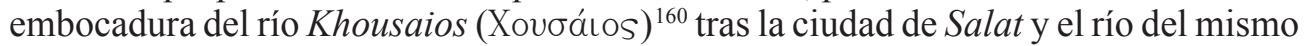
nombre (Bou Regreb). ${ }^{161}$ Lo que nos remite a la forma semita antigua para referirse a Etiopía $\left(K \bar{u}\right.$ š) y a los etíopes, como vemos en distintos textos bíblicos. ${ }^{162}$ Precisamente Flavio Josefo, ${ }^{163}$ al tratar el poblamiento mítico de África, señala: “de los cuatro hijos de Cam el tiempo no ha corrompido nada el nombre de Cuseo (Xovoaıov), ya que los etíopes, a quienes él gobernó, todavía incluso hoy son llamados Xovoaıo no sólo por ellos mismos, sino también por todos los habitantes de Asia". ${ }^{164}$ Cabe pues reconstruir la denominación fenicia de los "etíopes conductores de carros" a través de los términos grecizados Khousaioi Pharousioi, y por añadidura recoger la existencia de un río "etíope" en el entorno del Atlas bajo su arcaica denominación fenicia, Cusa y Cuseo.

153 Mela (III, 103) y Plinio (Nat. Hist. V, 46), a partir de una fuente común, sitúan a los Pharusii al lado de Hércules, cuando el héroe llegó a las Hespérides, identificándolos este último como persas (DESANGES 1980, 89).

154 FICKER 1978-1985.

155 Olmo Lete - Sanmartín 1996, 355.

156 Plin. Nat. Hist. V, 10.

157 Plin. Nat. Hist. VI, 195.

158 Según Desanges (1962, 212 y 233), por su localización y nombre hay que identificarlos con los Pharusii.

159 Ptol, VI, 6, 6. Cf. Desanges 1962, 218-219.

160 Ptol. IV, 6, 2.

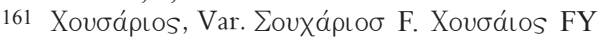

162 Ez. 27, 10; 30, 5; Ie. 46, 9; Is. 11, 11; Na. 3, 9.

163 Josef. $A I$ I, 131-132.

164 Trad. Vara Donado 1997, 44-45. De esta manera pretendía fijar la localización de uno de los nietos de Noé y sus descendientes, mencionados en la "tabla de los pueblos" del Génesis (10, 6), y correspondiente a la prole de Cam, que se habría diseminado por África y Canaán: Kūšs, Miṣrayim, Pūt, $K^{e} n \bar{a}^{e} a n$. 
Sin duda estos etíopes conductores de carros tirados por caballos deben relacionarse con las abundantes representaciones de carros asociados a equinos y armas de bronce y/o hierro del Alto Atlas, fechables desde época arcaica hasta época líbicobereber, momento en que son sustituidas por grabados de jinetes. ${ }^{165}$ Son especialmente abundantes en las estaciones rupestres de Oukaimeden, cerca de Marrakech, y del Yagour, también próxima. ${ }^{166}$ Este territorio, recorrido por los rheraya y los ourika en época histórica, así como la llanura de Marrakech, permanecieron como ámbito de trashumancia estival el primero y como pastos de invierno la segunda hasta el establecimiento del poder central en la llanura (s. XVI), sustrayéndoseles en esa época a los montañeses la ocupación del llano. ${ }^{167}$

Mientras tanto en el Sahara occidental y Mauritania los carros aparecen representados sin tiro o se asocian a bóvidos con cuernos y de forma rarísima al caballo, además las armas recogidas que se asocian a estos contextos son de cobre, no introduciéndose la metalurgia del hierro hasta bastante más tarde. ${ }^{168}$ Todo lo cual define un área del uso del carro tirado por caballos circunscrito a la vertiente septentrional del Alto Atlas con la llanura roja hasta el Tensift y a la vertiente sur hasta el uadi Draa, zona que se corresponde con la ocupación antigua de los Pharusii como aurigas de carros tirados por caballos señalada por Estrabón.

\section{Atlas, "montañas imponentes"}

Plinio recupera con minuciosidad una descripción costera extensa y muy precisa, en la que aparece incluida la denominación del Atlas considerada autóctona. Según se señala en el texto, a doscientas millas del río Fut se encuentra Addirim/Addiris,

165 Sobre la cronología de los carros dentro de los estilos de los grabados: MuzzoLini 1992, 147-154.

166 Véase Simoneau 1968-1972, 18; Jodin 1964. Los carros representados en el Atlas según MuzzolinI $(1988,381)$ proceden de una tradición asiria, fenicia, chipriota y de ciertos carros de Cirene por la posición del eje de las ruedas tras la plataforma del auriga. Sin embargo también hay representaciones de carros con el eje de las ruedas en el centro de la plataforma al menos en el Anti Atlas, en el uadi Eç Çayyad (WoLfF 1976, 56-63), carros que recuerdan por lo tanto a los grabados en las estelas del suroeste de la península Ibérica del Bronce Final-Hierro Antiguo, en los cuales la posición del eje es en la mitad de la plataforma, lo que nos remitiría a la tradición egea. Por ello parece plausible que las distintas formas de construir los carros fueron introducidas por varias vías y en distintos momentos, una de las cuales debe asociarse a la colonización fenicia de la costa norteafricana.

167 MAHDI 1999, 178, n.1.

168 Como en el caso de la región de El Rhallaouiya (Mauritania), donde además se han recogido en hábitat las mismas armas (de cobre) representadas en las plataformas rocosas con dataciones calibradas de C14 entre 2600 y 2430 BP en Bled Initi y de 2740 BP en Oued Chebbi (Vernet 1996, 72). Allí se aprecia el paso de una economía ganadera trashumante a otra de vocación guerrera creciente (VERNET 1996, 73). La escasez de caballos asociados a las representaciones de carros frente a bueyes de grandes cornamentas, muy abundantes, unido al armamento de cobre, indican la inferioridad de estos grupos en el nuevo contexto belicoso frente a los dueños de veloces carros uncidos a caballos y con armas de hierro. Sobre la permanencia en este ámbito de las armas de cobre ajenas al uso del estaño para endurecerlas puede verse GREBENART 1996. Las dataciones radiocarbónicas sin calibrar de la mina de cobre de Akjoujt (Guelb Moghreim), de la que proceden los objetos todos de cobre de la región sugieren una horquilla cronológica entre $826+-126$ a.C. y $400+-110$ a.C. (GREBENART 1992-1993). 
siendo éste el nombre de Atlas en la lengua de los indígenas. ${ }^{169}$ Más tarde Solino en sus Collectanea ${ }^{170}$ repite Addirim, igual que lo hace varios siglos después Marciano Capela, ${ }^{171}$ lo cual permitió a Th. Mommsen ${ }^{172}$ y más tarde a J. Desanges asegurar que ésta es la lectura correcta. ${ }^{173}$

Quizás, como habitualmente se ha venido sosteniendo, el topónimo grecizado Atlas pudiera derivar del término genérico pan-beréber adrar ${ }^{174}$ que designa "monte" o "montaña" 175 y que se utiliza para referirse a algunos macizos o zonas amesetadas, como Adrar de los Iforas (Mauritania), Adrar Bous en el desierto del Teneré, o la localidad de Adrar sobre una terraza del uadi Messaoud (Argelia). Menos convincente puede ser hacer derivar Addirim/Addiris de la palabra beréber, ya sea en singular o el plural más extendido, idraren. A este propósito apreciamos que Addirim ${ }^{176}$ es más próximo al fenicio-púnico 'drm (heb. *'addīrīm), con el que coincide incluso en vocalización. ${ }^{177}$ Se trata del plural del adjetivo 'addir, un término que en el ámbito de las lenguas semíticas se circunscribe al área cananea, pues aparece en ugarítico, fenicio-púnico y hebreo. Sus significados principales se relacionan con "poderoso", "fuerte", "magnífico", "principal", y por ello es un término utilizado frecuentemente para ensalzar o designar a dioses, jefes militares o reyes y élites urbanas en la epigrafía fenicio-púnica. ${ }^{178}$ Es un término que parece destacar la fuerza, como la potencia a veces incontenible de la naturaleza, ${ }^{179}$ pero también puede referirse a algo especialmente grande o magnífico en hebreo y ugarítico, ${ }^{180}$ igual que en fenicio-púnico puede destacar el carácter imponente de un accidente geográfico, como la punta especialmente destacada del cabo Tres Forcas (Rusaddir). " También en neopúnico está atestiguado el plural para referirse a un colectivo: "senadores/senado" con el significado literal "los grandes", "los poderosos", "los notables", ${ }^{182}$ pero se trata de una antiquísima denominación que vemos ya en Ugarit, donde adrm puede designar a los notables de un lugar, a veces reunidos igualmente en asamblea, tal y como aparece después en las inscripciones neopúnicas. ${ }^{183}$

169 Plin. Nat. Hist. V, 13.

170 Solin. Collectan XXIV, 15.

171 Capela VI, 667.

172 Mommsen 1895, viii-ix.

173 Desanges 1980, 51 y 133. No obstante, el investigador no se decide totalmente y en un trabajo más reciente considera que la tradición del texto no permite decantarse (DESANGES 1989, 1016).

174 WERNICKE 1986, col. 2119; THA IIA, 236, n. 478.

175 ChaKer 1985, 142; "aderar", "adrar", "idorar" = "montaña", cf. VillaVerde Vega 2001, 195, n. 815. El término se aplica a diversos accidentes geográficos de Mauritania.

176 Identificación que tratamos de forma extensa en LóPEZ PARDo 2007.

177 Véase Krahmalkov 2000, 37.

178 La raíz ' $d r$ "ser fuerte", "poderoso, "magnífico" se limita al área cananea. Sobre su uso en textos bíblicos, véase JENNI 1978-1985. Addir es un epíteto frecuente de Astarté, Sid, Isis, Tanit y Baal, algunas veces fijo (HofTIJZER - JoNGELING 1995, 18-19).

179 Ex. 15, 10; Ps. 93, 4.

180 Olmo Lete - Sanmartín 1996, 10.

181 Plin. Nat. Hist. V, 18; Ptol. IV 1; véase Ponsich 1992; López Pardo 2005, 169-171.

$182 K A I 119,4$ y $126,7$.

183 KTU 4, 246, 7; KTU 1, 17 V 7; Olmo Lete - SANMARTín 1996, 10. En ug. adrm como adjetivo plural con el sentido de fuerte, $K T U 4,4,2$. 
El término se utiliza para otros elementos relacionados con este entorno, el propio Plinio ${ }^{184}$ designa como portus Rhysaddir ${ }^{185}$ la que debía ser una bahía cerca de la actual Agadir, quizás conformada por el estuario del río Sous sin sus aportes aluvionarios recientes, y protegida por el gran promontorio del cabo Ghir, contrafuerte del Alto Atlas. El portus del $r$ 'š ' $d r(* R u \check{s}$-addir) sería naturalmente el fondeadero del

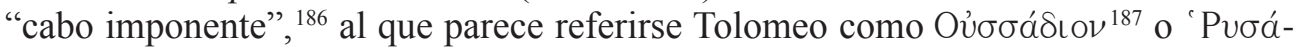

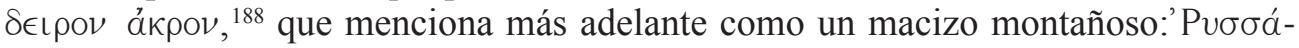
Sıov ỏpos (Fig. 6). ${ }^{189}$

\section{Dos nombres para el valle del Sous}

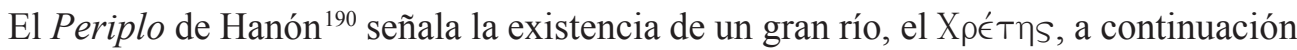
de haber dejado colonos en Kérnē y antes de llegar a un gran lago. Chretes parece muy cercano al Crathis descrito por Mnaseas, autor griego del S. III a.C., ${ }^{191}$ como un cauce fluvial que sale de un lago para desembocar en el Océano, en el cual viven aves que llaman meleágridas y penélopes; allí nace lo que llaman los mauri el electrum. ${ }^{192}$ Siguiendo las indicaciones del Periplo habría que convenir que se trata del Sous, el primer gran cauce fluvial después de Mogador y el cabo Ghir. Se trata con mucha probabilidad de una denominación fenicia del gran río que se encaja entre el Alto Atlas y el Anti-Atlas. Seguramente derivado del fenicio krt "cortar", "excavar". ${ }^{193} \mathrm{De}$ nombre comparable sería el torrente kerit frente al Jordán. ${ }^{194}$

También Plinio, ${ }^{195}$ recogiendo la información que le reportaba el periplo de Polibio, menciona el río Quosenus, ${ }^{196}$ que enumera tras el puerto Rhysaddir y antes del $\mathrm{Ma}$ sath (uadi Massa) y el Darat (uadi Draa), en cuyo caso se trata sin duda igualmente del río Sous. ${ }^{197}$ Con probabilidad es el mismo río Koú $\sigma a$ mencionado por Tolomeo. ${ }^{198}$

184 Plin. Nat. Hist. V, 9.

185 portum rhysaddir $A$ : rhisaddir $F 3$ risardir $D C h F E a C C o X$ risardis $R$ adir $F 1$ (Desanges 1980, 49).

186 “Cap puissant” (Desanges 1978, 135), “cap (du) Puissant” (LiPINSKi 1992) o volviendo a la tesis tradicional: "Powerful Cape" (LiPINSKi 2004, 466).

187 Ptol. IV 2 (Müller 1883-1901); transcrito por Roget (1924), Pointe d'Oussadion.

188 Este último según uno de los mejores manuscritos (DESANGEs 1978, 138; LiPINSKi 2004, 467).

189 Ptol. IV 6, 8.

190 Hano 9.

191 FHG III, 149-158; LiPINSKI 2004, 459. Seguramente no tenga nada que ver con el río Kpáßıs mencionado por Ps.-Escílax (112), que es identificable con el Sebú, pues se encuentra después del Lixos y un puerto llamado Thymiateria (Desanges 1978, 114).

192 Plin. Nat. Hist. XXVII, 37-38. Desanges 1978, 114.

193 Cf. HoftiJzer - Jongeling 1995, 538-539: krt "to cut" en fenicio (KAI 27, 8f), en púnico krty (KAI 181, $25)$; en hebreo bíblico, además del verbo $k r t$, se conocen sustantivos verbales como $k^{e} r u \overline{t o ̄ t}$ ("vigas cortadas") (KuTsch 1978-1985, col. 1172).

194 1Re. 17, 3 y 5.

195 Plin. Nat. Hist. V, 9.

196 quosenum $A E 2 C X h O x$ : uosenum DChFRCo quosenim E1 quosenuim a (DESANGES 1980, 49).

197 Desanges 1978, 135.

198 Ptol. IV, 1, 2. (Desanges 1980, 208 y n. 8). Pero se pregunta si no sería el Tensift, ya que en la desembocadura se elevaba en la Edad Media el ribat de Couz. 
El nombre tiene que ver con la raíz del semítico común qșṣ "cortar", "despedazar", 199 de la que proceden el ugarítico $q-s(-s)$ "trinchar" $(K T U 1,114,2)$ con idéntico significado que el hebreo qșh. ${ }^{200}$ De ello derivan el qșh fenicio (KAI 26A i 21) y púnico $q s{ }^{\prime} h(K A I 173,3)$ con el significado de "fin", "límite", 201 igual que el hebreo qē ${ }^{202}$ y el ugarítico $q S{ }^{203} \mathrm{Si}$ antes hemos relacionado Chretes/Crathis con el fenicio krt "cortar", "excavar" referido al Sous, habríamos de suponer fundadamente que el Cousa (igualmente identificado con el Sous) se relaciona con $q s$ en su acepción de "cortar", aunque siempre cabe que en ambos casos puede hacer referencia a un "río del confín". En este sentido, la variante expuesta en el periplo de Polibio, Quosenus, ofrece similitudes con el adjetivo en hebreo bíblico qișōn "último", "extremo". ${ }^{204}$ Ante la imprecisión de su sentido en referencia al río Sous, caben diversas posibilidades, como "el último" en el caso de que tenga un significado confinal, o mejor en relación con "cortar", como el cauce que sirve de límite o corte al Alto Atlas, que tiene sus máximas cumbres, de más de 4000 metros, precisamente en la vertiente del valle del Sous, en su curso medio y bajo. En suma, contamos con dos nombres fenicio-púnicos de significado muy similar para nombrar el río Sous.

El caso es que si recapitulamos sobre los últimos datos, el Alto Atlas como los Addirim, el promontorio, el monte y el puerto denominado $R u$ š-addir referido al entorno del cabo Ghir y las dos denominaciones del Sous, Chretes y Quosenus, se nos presenta una notable concentración de toponimia fenicio-púnica en este ámbito, que sin duda tuvo que ver con la presencia fenicia en Mogador y seguramente con alguna factoría o colonia en el estuario del Sous (Fig. 6). Desgraciadamente la fuerte actividad antrópica en esta zona sobre todo en época reciente y los aportes aluviales del río, harán cuando menos muy difícil la localización de vestigios de época fenicio-púnica en el entorno.

Con respecto a todo el recorrido que hemos realizado desde el cabo Espartel, apreciamos en primer lugar la permanencia de una toponimia fenicio-púnica mucho más abultada de lo que se había sospechado en los testimonios griegos y latinos que se nos han conservado. Ésta toca lo mismo promontorios como el Soloeis, el cabo de Melqart o el Rušaddir, montes costeros como los Addirim (Alto Atlas), estuarios de ríos, como el Lkš (Lucos), el Sbb (Sebú) o el Chretes/Cousa-Quosenus (Sous). Lagunas y abrigos portuarios como el 'gn (Tahadart) y Mismar (Moulay Bouselham) y la isla de Qrn (Mogador), la única de esta costa ocupada en la Antigüedad. Pero también, y quizás es lo más novedoso, pueblos como los habitantes del har 'anbin o har 'anbi y los etíopes Pharousii, los primeros reconocidos a partir de los recursos de su tierra y los segundos más etnográficamente por lo que más les caracteriza, sus carros. Sus localidades, frente a lo que muchas veces se ha dicho de algunas de ellas, también contaban con nombres fenicios, Lkš (Lixus), Ro’š (Akra, act. Kuass ?), har 'anbi, Guttē,

199 WAGNER 1978-1985, col. 830.

200 Olmo Lete - Sanmartín 1996, 376.

201 Fuentes Estañol 1980, 223; “end”, “border”, “edge” (HoftiJzer - Jongeling 1995, 1021).

202 WAGNER 1978-1985, col. 830.

203 (1) "extremo", "borde", "confín” KTU 1, 6 II 11, (2) “filete de carne” KTU 1, 3 I 8; Olmo LetE - SANMARTÍN 1996, 375.

204 Cf. Wagner 1978-1985, col. 831. 
zll (Zilil, act. Dchar Jdid), Krk (Karikon, act. Xeraka ?), 'šlyt (Asilah ?) y finalmente Mgdl qrn (Mogador). En suma, la toponimia costera parece surgir o adaptarse a las necesidades de los navegantes, para servirles de elementos de referencia, "el monte de las uvas" o "las viñas", un primer "confín" en el río Lucos, "el cabo poderoso", "el abrigo", la isla en forma de cornamenta, ríos como "el de los grandes meandros", "el río cortado" o "del corte/confín", etc. Los asentamientos reciben nombres que permiten reconocerlos fácilmente, como la localidad del "promontorio", "la fortaleza", "el lugar protegido", "la pesquería", "la prensa de vino" o "aceite", la localidad "del monte de las uvas" o "las viñas", etc.

\section{Bibliografía}

Akerraz, A. ET ALII (1981-1982): "Fouilles de Dchar Jdid, 1977-1980", BAM 14, 169244.

Aranegui Gascó, C. - Kbiri Alaoui, M. - Vives-Ferrándiz Sánchez, J. (2004): “Alfares y producciones cerámicas en Mauritania occidental. Balance y perspectivas", [en] Fliginae Baeticae: talleres alfareros y producciones cerámicas en la Bética romana (ss. II a.C. - VII d.C.), Cádiz, 363-378.

Ballouche, L. (1986): Paléoenvironnement de l'homme fossile holocène au Maroc. Apport de la palynologie, Bordeaux.

Belmonte Marín, J. A. (2002): "Presencia sidonia en los circuitos comerciales del Bronce Final", RStudFen 30, 3-18.

Blázquez y Delgado Aguilera, A. (1921): "Las costas de Marruecos en la Antigüedad", BAHist 79, 400-418 y 481-509.

BochaRT, S. (1646): Geographia sacra pars prior: Phaleg, seu de dispersione gentium et terrarum divisione facta in aedificatione turris Babel, Cadomi.

Bonnet, C. (1988): Melqart: cultes et mythes de l'Héraclès tyrien en Méditerranée, ( =Studia Phoenicia VIII), Leuven.

Boube, J. (1981): "Les origines phéniciennes de Sala de Maurétanie" BCTH(B) 17, 155-170.

Carcopino, J. (1949): "Du périple d'Hannon aux portulans grecs du XVIe siècle", [en] Mélanges d'archéologie et d'histoire offerts à Ch. Picard (=RA 29-32), Paris, 132-141.

Chaker, S. (1985): “Adrar, montagne”, [en] G. Camps - S. Chaker (eds.), Encyclopédie Berbère II, Aix-en-Provence, 142.

Cintas, P. (1954): Contribution à l'étude de l'expansion carthaginoise au Maroc, Paris.

Desanges, J.

(1962): Catalogue des tribus africaines de l'Antiquité classique à l'ouest du Nil, Dakar. 
(1978): Recherches sur l'activité des Méditerranéens aux confins de l'Afrique (VIe siècle avant J.-C. - IVe siècle après J.-C.), Roma.

(1980): Pline l'Ancien. Histoire Naturelle V, 1-46. Première partie (L'Afrique du Nord), Paris.

(1989): “A 311 Atlas. Antiquité”, [en] G. Camps - S. Chaker (eds.), Encyclopédie Berbère, Aix-en-Provence, 1013-1017.

Despois, J. - Raynal, R. (1967): Géographie de l'Afrique du Nord Ouest, Paris.

El BeKri, A. O. (1911-1913): Description de l'Afrique septentrionale par Abou Obeîd el-Bekri, Paris.

FantaR, M. H. (2002): "Matériaux phénico-puniques dans la version grecque du Périple d'Hannon" [en] M. Khanousi - P. Ruggeri - C. Vismara (eds.), L'Africa Romana 14, Roma, 75-82.

Fernández Galiano, M. - Pabón, J. M. (2000): Homero. Odisea (=Biblioteca Clásica Gredos), Madrid.

Ficker, R. (1978-1985): “rkb”, [en] E. Jenni - C. Westermann (eds.), Diccionario teológico manual del Antiguo Testamento, Madrid, cols. 978-983.

Fuentes Estañol, M. J. (1980): Vocabulario fenicio, Barcelona.

GREBENART, D.

(1992-1993): "L'âge du cuivre au Sahara central et occidental", Sahara 5, 49-58. (1996): "Les premiers métaux en Afrique de l'Ouest", [en] G. Aumassip (ed.), La préhistoire de l'Afrique de l'Ouest, Saint-Maur-des-Fossés, 75-82.

HaBiBi, M. (1992) : "La céramique à engobe rouge phénicien de Lixus", [en] Lixus. Actes du colloque de Rabat, Roma, 27-44

HalfF, G. (1963-1964): “L'onomastique punique de Carthage”, Karthago 12, 63-145.

Heubeck, A. - West, S. T. - Hainsworth, J. B. (1988): A commentary on Homer's Odysey, Oxford.

HoftiJzer, J. - Jongeling, K. (1995): Dictionary of the North-West semitic inscriptions, Leiden.

JenNi, E. (1978-1985): “'addir”, [en] E. Jenni - C. Westermann (eds.), Diccionario teológico manual del Antiguo Testamento, Madrid, cols. 86-90.

Jodin, A.

(1957): "Note préliminaire sur l'établissement pré-romain de Mogador (campagnes 1956-1957)", BAM 2, 9-40.

(1964): "L'âge du bronze au Maroc: la nécropole mégalithique d'El Mries" BAM 5, 11-45.

(1966): Mogador. Comptoir phénicien du Maroc Atlantique, Tanger.

KBIRI Alaoui, M.

(2000): “À propos de la chronologie de la nécropole rurale d'Aïn Dalia Lekbira (région de Tanger, Maroc)", [en] M. E. Aubet - M. Barthélemy (eds.), Actas del IV Congreso Internacional de Estudios Fenicios y Púnicos, Cádiz, 1185-1196. 
(2007): Revisando Kuass (Asilah, Marruecos). Talleres cerámicos en un enclave fenicio, púnico y mauritano, Valencia.

Kbiri Alaoui, M. - López Pardo, F. (1998): "La factoría fenicia de Mogador (Essaouira, Marruecos): las cerámicas pintadas", AEspA 71, 5-25.

KIDD, I.G. (1988): Posidonius II: The commentary, Cambridge.

Krahmalkov, C. R. (2000): Phoenician-Punic dictionary (=Studia Phoenicia XV), Leuven.

Kutsch, E. (1978-1985): “Krt”, [en] E. Jenni - C. Westermann (eds.), Diccionario teológico manual del Antiguo Testamento, Madrid, cols. 1171-1176.

Le Glay, M. (1992): "Dchar Djedid", [en] E. Lipinski, Dictionnaire de la civilization phénicienne et punique, Bruxelles, 127.

Levi della Vitta, G. - Amadasi Guzzo, M. G. (1987): Inscrizioni puniche della Tripolitania [1927-1967], Roma.

LIPINSKI, E.

(1992): Dictionnaire de la civilisation phénicienne et punique, Bruxelles.

(1994): "L'aménagement des villes dans la terminologie phénico-punique", [en] A. Mastino - P. Ruggeri (eds.), L'Africa romana 10, Sassari, 121-133.

(1995): Dieux et déesses de l'univers phénicien et punique (=Studia Phoenicia XIV), Leuven.

(2000): "Vestiges puniques chez al-Bakrî", [en] M. Khanoussi - P. Ruggeri - C. Vismara (eds.), L'Africa romana 13, Roma, 283-287.

(2004): Itineraria Phoenicia (=Studia Phoenicia XVIII), Leuven-Paris-Dudley.

LÓPEZ PARDO, F.

(1990): "Nota sobre las ánforas II y III de Kuass (Marruecos)", AntAfr 26, 13-23.

(1990a): "Sobre la expansión fenicio-púnica en Marruecos. Algunas precisiones a la documentación arqueológica", AEspA 63, 7-41.

(2000): El empeño de Heracles. La exploración del Atlántico en la Antigüedad, Madrid.

(2001): "Del mercado invisible (comercio silencioso) a las factorías-fortaleza púnicas en la costa atlántica africana", [en] P. Fernández Uriel - C. González Wagner - F. López Pardo (eds.), Intercambio y comercio preclásico en el Mediterráneo, Madrid, 216-234.

(2004-2005): "Dioses en los prados del confín de la tierra: un monumento cultual con betilos de Lixus y el Jardín de las Hespérides", Byrsa 3-4, 303-350.

(2005): "La fundación de Rusaddir y la época púnica", [en] A. Bravo Nieto - P. Fernández Uriel (eds.), Historia de Melilla, Melilla, 165-189.

(2005a): "Tingentera, Tingi y el mito de Anteo", Mayurqa 30, 567-575.

(2007): "Un nombre para Atlas", [en] Homenaje a Juan Cascajero (=Gerión Extra), Madrid, 131-140.

(2008): “Las naves de Kerné I. Las referencias literarias", [en] P. Fernández Uriel - C. González Wagner - F. López Pardo (eds.), Fenicios, púnicos y el Atlántico, Madrid, 51-68. 
López Pardo, F. - HabiBi, M. (2001): "Le comptoir phénicien de Mogador. Approche chronologique et céramique à engobe rouge", [en] Actes des Premières Journées Nationales d'Archéologie et du Patrimoine, Rabat, 53-63.

López Pardo, F. - Mederos Martín, A. - Ruiz Cabrero, L. Á. (2007): "Sistemas defensivos en la toponimia fenicia de la costa atlántica”, [en] J. L. López Castro (ed.), Las ciudades fenicio-púnicas en el Mediterráneo Occidental, Almería, 383-404.

López Pardo, F. - Ruiz Cabrero, L. Á. (2005): "Inscripción fenicia arcaica de Lixus", $M D A I(M)$ 46, 46-60. (2006): "Marinos, comerciantes y metalúrgicos en Kerné. La onomástica", Mainake 28, 213-241.

López Pardo, F. - Suárez Padilla, J. (2002): “Traslados de población entre el Norte de África y el sur de la Península Ibérica en los contextos coloniales fenicio y púnico", Gerión 20/1, 113-152.

LuQueT, A.

(1956): "Prospection punique de la côte atlantique du Maroc", Hespéris 43, 117132.

(1973-1975): "Contribution à l'atlas archéologique du Maroc. Le Maroc punique", BAM 9, 237-328.

Mahdi, M. (1999): Pasteurs de l'Atlas. Production pastorale, droit et rituel, Casablanca.

MANFREDI, L. I. (1985): "Rsmlqrt, r'smlqrt: nota sulla numismática púnica di Sicilia", RIN 7, 3-8.

Mazard, J. (1955): Corpus Numorum Numidiae Mauretaniaque, Paris.

Mommsen, Tн. (1895): C. Iulii Solini Collectanea Rerum Memorabiliorum, recensuit Th. Mommsen, Berolini.

Müller, C. (1883-1901): Claudii Ptolemai Geographia, Paris.

Muzzolini, A.

(1988): "Les chars des stèles du sud-ouest de la Péninsule Ibérique, les chars des gravures rupestres du Maroc, et la datation des chars sahariens", [en] I Congreso internacional El Estrecho de Gibraltar, Madrid, 361-387.

(1992): "Dating the Earliest Central Saharan Rock Art: archaeological and linguistic data", [en] R. Friedman - B. Adams (eds.), The followers of Horus: studied dedicated to Michaes Allen Hoffman, 1944-1990, Oxford, 147-154.

Olmo Lete, G. (1981): Mitos y leyendas de Canaán según la tradición de Ugarit, Valencia.

Olmo Lete, G. - Sanmartín, J. (1996): Diccionario de la lengua ugarítica, Sabadell.

Onrubia Pintado, J. (1988): "Modalidades, implicaciones y significación de las relaciones prehistóricas ibero-magrebíes. Problemas y perspectivas", [en] E. Ripoll (ed.), Actas del Congreso Internacional "El Estrecho de Gibraltar" I, Ceuta, 147171. 
Ponsich, M.

(1964): “Contribution à l'atlas archéologique du Maroc: région de Tanger”, BAM 5, 253-290.

(1967): Nécropoles phéniciennes de la région de Tanger, Tanger.

(1968): Alfarerías de época fenicia y púnico-mauritana en Kuass (Arcila, Marruecos), Valencia.

(1970): Recherches archéologiques à Tanger et dans sa région, Paris.

(1982): “Territoires utiles du Maroc punique", [en] H. G. Niemeyer (ed.), Phönizier im Westen, Mainz, 429-444.

(1992): "Rusaddir", [en] E. Lipinski, Dictionnaire de la civilization phénicienne et punique, Bruxelles, 379.

Quintero Atauri, P. (1940-1941): "Nueva estación prehistórica en el Marruecos Español", $A \operatorname{Esp} A$ 14, 563-564.

REBUFFAT, R.

(1974): "Vestiges antiques sur la côte occidentale de l'Afrique au sud de Rabat", AntAfr 8, 25-49.

(1976): “D’un portulan grec du XVIe siècle au Périple d'Hannon”, Karthago 17, 139-151.

Rebuffat, R. - Hallier, G. - Marion, J. (1970): Thamusida (=Fouilles des Services des Antiquités du Maroc II), Paris.

Roget, R. (1924): Le Maroc chez les auteurs anciens, Paris.

Ruiz Mata, D. (1999): “La fundación de Gadir y El Castillo de Doña Blanca: contrastación textual y arqueológica", Complutum 10, 279-317.

Signes Codoñer, J. (ED.), (2004): Escritura y literatura en la Grecia arcaica, Madrid.

Simoneau, A. (1968-1972): "Nouvelles recherches sur les gravures rupestres du HautAtlas et du Draa", BAM 8, 15-33.

Souville, G. (1988): "Les hommes du chalcolithique et du bronze ont traversé le détroit de Gibraltar", [en] E. Ripoll (ed.), Actas del Congreso Internacional "El Estrecho de Gibraltar” I, Ceuta, 285-292.

Stolz, F. (1978-1985): “Siyyōn”, [en] E. Jenni - C. Westermann (eds.), Diccionario teológico manual del Antiguo Testamento, Madrid, cols. 684-694.

Stumme, F. (1912): “Gedanken über libysch-phönizische Anklänge”, ZfAssyr 27, 121-128.

Vana Donado, J. (1997): Flavio Josefo. Antigüedades judías, Madrid.

VERNET, R. (1996): “Un exemple de corrélation entre char et métal dans l'art rupestre mauritanien", [en] G. Aumassip (ed.), La préhistoire de l'Afrique de l'Ouest, Saint-Maur-des-Fossés, 69-73.

Villard, F. (1960): “Céramique Grecque du Maroc”, BAM 4, 1-26.

VillaVerde Vega, N. (2001): Tingitana en la antigüedad tardía (siglos III-VII): autoctonía y romanidad en el extremo occidente mediterráneo (=Bibliotheca Archaeologica Hispana 11), Madrid. 
Von Soden, W. (1959): "Die Eremboi der Odyssee und die Inrfahrt des Menelaos", WS 72, 26-29.

Wagner, M. (1978-1985): “qes", [en] E. Jenni - C. Westermann (eds.), Diccionario teológico manual del Antiguo Testamento, Madrid, cols. 830-835.

Wernicke, K. (1896): “Atlas”, RE II/2, cols. 2118-2133.

WolfF, R. (1976): “Chars schématiques de l'oued Eç Çayyad”, BAM 10, 53-69 